\title{
Real Asset Returns and Components of Inflation: A Structural VAR Analysis
}

\author{
M. Hagmann ${ }^{a}$ \\ C. Lenz ${ }^{b}$
}

First Version: October 2004

This Version: April 2005

\begin{abstract}
We shed new light on the negative relationship between real stock returns or real interest rates and (i) ex post inflation, (ii) expected inflation, (iii) unexpected inflation and (iv) changes in expected inflation. Using the structural vector autoregression methodology, we propose a decomposition of those series into economically interpretable components driven by aggregate supply, real demand and money market shocks. Our empirical results support Fama's 'proxy hypothesis' and the predictions of several general equilibrium models. Concerning the negative relation between the real rate of interest and inflation, we find that the Mundell-Tobin model and the explanation of Fama and Gibbons (1982) are not competitors: both add insight in their own way about the reasons for the negative correlation between those variables. However, the importance of the latter explanation has decreased since the 1980's.
\end{abstract}

Key words and phrases: real stock returns, real rate of interest, expected and unexpected inflation, 'Fisher hypothesis', structural VAR.

JEL Classification: E44, G1

${ }^{a}$ HEC Lausanne and FAME, Institute of Banking and Finance, Route de Chavannes 33, CH-1007 Lausanne.

E-mail: matthias.hagmann@unil.ch.

${ }^{b}$ University of Basel, Department of Economics (WWZ), Petersgraben 51, CH-4003 Basel.

E-mail: carlos.lenz@unibas.ch. 


\section{Introduction}

This article reexamines the empirical relation between real stock returns and different components of inflation, namely (i) ex post inflation, (ii) expected inflation, (iii) changes in expected inflation and (iv) unexpected inflation. In the seventies it has often been argued that common stocks offer a hedge against inflation. The theoretical basis for this assertion is the Fisherian view of the world, which assumes that stocks represent ownership of physical capital assets. Their real values should therefore be independent of the rate of inflation.

Contrary to this common view, stock market performance since the 1950's seems to contradict this. Several studies report a negative correlation between real stock returns and the above mentioned inflation components in the U.S. and other countries [e.g. Lintner (1975), Bodie (1976), Jaffe and Mandelker (1976), Nelson (1976), and Fama and Schwert (1977), and Solnik (1983)]. Boudoukh and Richardson (1993) find that the negative relation decreases to some extent when longer time horizons are considered. The import of those studies is that real rates of return cannot be considered as independent of inflation as suggested by the Fisher hypothesis. Fama $(1981,1983)$ argues that the correlation between real stock returns and inflation is spurious and just proxies for a more fundamental relationship. He brings forth a large amount of evidence showing that real activity and real stock returns are positively related. Furthermore, he argues that whereas nominal money is mainly exogenously determined, real money demand is procyclical. Therefore, the additional demand for real money induced by higher real activity can only be satisfied by a fall in the price level. These two effects jointly imply that real stock returns and inflation are negatively, but spuriously related. Geske and Roll (1985) strengthen Fama's hypothesis but argue in addition that nominal money supply is countercyclical. The reason being that a decrease in economic activity increases the federal deficit which is then partly monetized. This leads to an expected increase in the growth rate of money and therefore to a larger increase in inflation than if there were no negative relation between real activity and the growth rate of the money supply.

Similarly to real stock returns, it has also been found that the real interest rate is negatively correlated with expected inflation. The explanation of Mundell (1963) and Tobin (1965) for this phenomenon is that higher expected inflation increases the opportunity cost of holding money and therefore induces shifts from money into bonds which depresses the equilibrium real interest rate. This lower cost of capital then induces a boom in investment and real activity, which implies that the real interest rate and real economic activity are negatively correlated. Contrary to this, Fama and Gibbons (1982) find, that the real interest rate is not negatively, but positively correlated with real activity. In their story, one side of the coin is the procyclical money demand argument of Fama (1981), which induces the negative correlation between real 
activity and inflation. The other side of the coin is that expected increases in real activity induce higher investments. To finance those investments, the equilibrium real interest rate has to raise in order to shift enough resources from consumption to savings.

Concerning real stock returns and different components of inflation, there have been several theoretical attempts to explain the negative correlation between these series. Danthine and Donaldson (1986) provide a rational expectations equilibrium model. Their analysis implies a negative relation between real stock returns and inflation induced by real output shocks. However, stocks provide a long-run hedge against inflation induced by pure monetary shocks. Day's (1984) analysis suggests that the negative correlation between real stock returns and the expected and unexpected component of inflation is driven by shocks to the production process. These shocks contain information about the distribution of future economic events. Stulz (1986) presents an equilibrium model in which the endogenously determined expected real rate of return on stocks and the real rate of interest are both negatively related to the expected level of inflation. Expected inflation due to money shocks induces a smaller reduction in expected real stock returns than expected inflation due to real shocks. Similarly to Danthine and Donaldson, the equilibrium monetary asset pricing model of Marshall (1992) predicts that the correlation between ex post measures of real stock returns and inflation is negative when induced by real shocks, but positive when induced by monetary shocks. Furthermore, for the relation between expected real stock returns and expected inflation, Marshall's analysis implies that the negative correlation is stronger when it is driven by shocks to real economic activity than by monetary shocks. All those theoretical attempts have a common feature: The sign and strength of the theoretically justified negative correlation between real asset returns and different components of inflation depend on the economic source of the shocks, namely real and monetary shocks.

Several studies examine the negative relation between real stock returns and inflation using vector autoregressive models: James, Koreisha and Partch (1985), Lee (1992), Balduzzi (1995) and more recently Hess and Lee (1999) and Gallagher and Taylor (2002). The first three studies are nonstructural and therefore provide no information about the nature of the economic shocks driving the negative relation between real stock returns and different components of inflation. By using a bivariate structural vector autoregressive model (SVAR), Hess and Lee (1999) decompose real stock returns and inflation into two components driven by aggregate supply and aggregate demand shocks. They find that the negative relation between real stock returns and ex post inflation is induced by aggregate supply shocks, whereas a positive relation is induced by aggregate demand shocks. The overall negative sign results because supply shocks are more important for the relationship between real stock returns and inflation in the post- 
World War II period. Gallagher and Taylor (2002) follow Hess and Lee (1999), but include real output growth instead of real stock returns in their SVAR model.

In this paper, we decompose real stock returns, the real interest rate and different components of inflation into economically interpretable elements driven by aggregate supply (AS), real demand (RD) and money market (MM) shocks. Our empirical study differs from previous work for the following reasons: First, we identify structural shocks by using sound economic theory and do not restrict our empirical analysis to the bivariate case ${ }^{1}$. This allows us to divide demand shocks into monetary and non-monetary demand shocks. Second, in our framework, we can assess the relative importance of various structural shocks over different time horizons for the relationship between real stock returns and (i) ex post inflation, (ii) expected inflation, (iii) unexpected inflation and (iv) changes in expected inflation. Previous work around SVARs just considered the relationship between real stock returns and ex post inflation, although the most puzzling result of all is the negative correlation with expected inflation, which contradicts the Fisher hypothesis. Third, in the same framework we are also able to examine the relation between the real rate of interest and expected inflation, as well as its relation to real stock returns. This is possible since we use a reduced form VAR analysis to get empirical proxies for different inflation components. These proxies are then decomposed in a second step into structurally interpretable components using the SVAR methodology. This approach is novel in the literature and allows us to examine theoretical predictions concerning the joint dynamics of real stock returns or the real rate of interest and different components of inflation over different time horizons. Last but not least from a computational and technical point of view, unlike previous work, we deliver small sample bias corrected confidence intervals for the impulse response functions and conditional correlations based on the bootstrap procedure described in Kilian (1998).

Concerning the relationship between real stock returns and unexpected inflation, our empirical results are in line with Fama (1981), Danthine and Donaldson (1986), and Marshall (1992). The predictions of the latter paper concerning the negative relation between real stock returns and expected inflation are also confirmed by our empirical findings.

Concerning the relation between the ex ante real rate of interest and expected inflation, we find support for Fama and Gibbons (1982), as well as for Mundell (1963) and Tobin (1965). We will show that the predictions of these authors largely depend on whether an expected increase in real activity is induced by an AS shock with permanent effect or a MM shock with temporary effect.

The article is organized as follows. Section I describes how we measure different components of inflation, presents the SVAR methodology and introduces the concept of conditional 
covariance decomposition used in this paper. In this section we also discuss the various identification assumptions we make to recover structural shocks. Section II discusses the empirical findings using U.S data, presents robustness results considering different identification schemes and compares our results to previous empirical work. Section III summarizes and concludes.

\section{Econometric Methodology}

We first describe the construction of empirical proxies for expected and unexpected inflation by using a vector autoregressive model (VAR). We then go on to interpret this VAR model as the reduced form of a structural VAR model (SVAR) and discuss different identification schemes. Furthermore, we develop an extended version of the concept of conditional covariance decomposition.

\section{A. Measuring expected and unexpected inflation}

In order to examine the contemporaneous relationship between real stock returns or the real rate of interest and different components of inflation, a model is necessary to measure those components empirically. A series of authors, e.g. Jaffe and Mandelker (1976) and Fama and Schwert (1977), follow Fama (1975) in using short term interest rates as predictors for inflation. The change in expected inflation is simply measured as the change in the short term interest rate. Unanticipated inflation is the ex post difference between the actual rate of inflation and the beginning of period interest rate. Other authors, e.g. Bodie (1976) and Nelson (1976) use univariate ARIMA models to get empirical proxies of the different inflation components. For a comparison of these approaches, see Schwert (1981).

In this paper, we propose to measure different components of inflation by using vector autoregressions. Consider a $3 \times 1$ vector $x_{t}$ containing the growth rate of real stock prices $\left(\Delta s p_{t}\right)$, the real interest rate $\left(i_{t}-\pi_{t}\right)$, and inflation $\left(\pi_{t}\right)$. The date $t$ nominal interest rate $i_{t}$ is the risk free predetermined rate of return of a Treasury Bill, running in period $t$, and is therefore measured at the beginning of the period. The inclusion and definition of the variables in our vector autoregressive system is driven by the empirical question we want to address. We applied the augmented Dickey-Fuller (ADF) and the Phillips-Perron (PP) unit root tests to the above mentioned series. Both tests agree that real stock returns and the real interest rate are stationary. The ADF test was not able to reject the presence of a unit root in the inflation rate. However, the ADF test is known to have low power. The PP test clearly indicates 
stationarity of all series which is taken as granted in the sequel. We assume that the variables in $x_{t}$ have joint dynamics which can be described by a VAR of order $q,{ }^{2}$

$$
\begin{aligned}
x_{t} & =D_{1} x_{t-1}+D_{2} x_{t-2}+\ldots+D_{q} x_{t-q}+\epsilon_{t} \\
& =E\left[x_{t} \mid x_{t-1}, \ldots, x_{t-q}\right]+\epsilon_{t} \\
E\left(\epsilon_{t} \epsilon_{t}^{\prime}\right) & =\Omega,
\end{aligned}
$$

where $\Omega$ is the covariance matrix of the disturbance terms which is in general non-diagonal. The VAR model in (2.1) can be estimated equation by equation using ordinary least squares. Once this system is estimated, empirical proxies for the expected and unexpected parts of inflation in period $t, \pi_{t}^{e}$ and $\pi_{t}^{u}$ respectively, can be calculated as

$$
\begin{aligned}
\pi_{t}^{e} & =e_{3}^{\prime}\left(\hat{D}_{1} x_{t-1}+\hat{D}_{2} x_{t-2}+\ldots+\hat{D}_{q} x_{t-q}\right), \\
\pi_{t}^{u} & =e_{3}^{\prime} \hat{\epsilon}_{t}
\end{aligned}
$$

where $\hat{D}_{j}$ and $\hat{\epsilon}_{t}$ are estimates of the coefficients and disturbance vector in (2.1), and $e_{3}$ is a vector containing 1 in the third line and zero elsewhere.

This multivariate approach of measuring different inflation components has several advantages. Compared to univariate time series models, VAR models allow us to incorporate more information than just the past dynamics of the own series to predict future inflation rates and therefore should provide more precise proxies for expected and unexpected inflation. Furthermore, our measures of expected and unexpected inflation are orthogonal to each other and the unexpected inflation component has zero mean by construction. These properties do not hold if one uses short term interest rates as proxies for expected inflation.

The main advantage of our measurement method arises, however, in connection with the structural VAR methodology. The structural VAR will allow us to assess which kind of economic shocks drive the different components of inflation, which are themselves measured by the reduced form VAR as demonstrated in (2.2). In particular, we are able to answer the question what economic forces drive the negative relationship between the real rate of interest or real stock returns and different components of inflation.

Before turning to SVAR models, some remarks concerning the timing of the variables which enter our VAR model are appropriate. Since we use quarterly data, not all data are known at the end of the quarter. We lack inflation for the last month of the quarter, which is just publicly released in the first month of the new quarter. This announcement may in fact convey little or no incremental information to the market beyond that available in the meantime from other sources (such as direct observations by market participants), we refer to Nelson (1976) 
for details. Furthermore, a monthly model for inflation could be constructed to get accurate proxies for the last month of the quarter. We, therefore, consider this issue of minor importance in the present context.

\section{B. Structural vector autoregressive model}

In this subsection we will concentrate on the identification of unobserved exogenous structural shocks, influencing the dynamics of $x_{t}$. We assume that $x_{t}$ has a structural vector autoregressive representation

$$
\sum_{s=0}^{q} B_{s} x_{t-s}=B(L) x_{t}=u_{t},
$$

where $u_{t}=\left[u_{t}^{A S}, u_{t}^{R D}, u_{t}^{M M}\right]^{\prime}$ contains mutually uncorrelated structural shocks with unit variance, $E\left(u_{t} u_{t}^{\prime}\right)=I$. Furthermore, $B(L)=B_{0}+B_{1} L+B_{2} L^{2}+\ldots+B_{q} L^{q}$, where $L$ is the lag-operator defined as $L^{i} x_{t}=x_{t-i}$.

The reduced form VAR representation is

$$
\begin{aligned}
\sum_{s=0}^{q} D_{s} x_{t-s} & =D(L) x_{t}=\epsilon_{t}, \\
D_{s} & =B_{0}^{-1} B_{s}, \\
\Omega & =E\left(\epsilon_{t} \epsilon_{t}^{\prime}\right)=B_{0}^{-1}\left(B_{0}^{-1}\right)^{\prime} .
\end{aligned}
$$

Since the model in (2.4) is a reduced form, $D_{0}$ equals the identity matrix $I$.

The starting point for the analysis of a structural VAR is the estimation of the reduced form VAR (2.1) including sufficient lags in order to describe the underlying dynamics of the variables of interest. The covariance matrix of the residuals $\epsilon_{t}$ is, in general, nondiagonal. For an economically meaningful interpretation of the dynamics of the system, it has to be identified. The reduced form model with correlated errors has to be transformed into a structural infinite moving average form with uncorrelated, economically interpretable shocks. Once this system is obtained, the dynamic impact of structural shocks on the variables in $x_{t}$, the impulse response function, can be examined. 
To recover structural shocks from reduced form disturbances, we invert in a first step an estimate of the reduced form VAR (2.4) to obtain the Wold VMA representation. The properties of the system ensure that

$$
x_{t}=\sum_{s=0}^{\infty} C_{s} \epsilon_{t-s}=C(L) \epsilon_{t},
$$

where $C_{0}$ is the identity matrix by construction. A popular strategy to identify a set of uncorrelated shocks has been introduced in Sims (1980). To obtain identification, Sims assumed that the contemporaneous interaction between the variables follows a recursive structure. More formally: Let $\tilde{\Omega}$ denote the Choleski decomposition of $\Omega=\tilde{\Omega} \tilde{\Omega}^{\prime}$. Then we can write

$$
\begin{aligned}
x_{t} & =\sum_{s=0}^{\infty} C_{s} \tilde{\Omega} \tilde{\Omega}^{-1} \epsilon_{t-s} \\
& =\sum_{s=0}^{\infty} A_{s} u_{t-s}=A(L) u_{t},
\end{aligned}
$$

where $A_{s}=C_{s} \tilde{\Omega}$. By construction the shocks $u_{t}$ are mutually uncorrelated. Furthermore, since $\tilde{\Omega}^{-1}$ is lower triangular, the shock $u_{t}^{j}$ has an impact on $x_{t}^{j^{\prime}}$ in the same period only if $j^{\prime} \geq j$, where $u_{t}^{j}$ denotes the $j^{\text {th }}$ component of the innovation vector $u$. However, although the Choleski factorization is unique, this is not the only way to obtain a set of mutually uncorrelated shocks. Any reordering of the variables in $x_{t}$ yields different results. To illustrate this, take any orthogonal matrix $R$, meaning that $R R^{\prime}=I$, then

$$
\begin{aligned}
x_{t} & =\sum_{s=0}^{\infty} A_{s} R R^{\prime} u_{t-s} \\
& =\sum_{s=0}^{\infty} A_{s}^{(R)} u_{t-s}^{(R)}
\end{aligned}
$$

where $A_{s}^{(R)}=A_{s} R$, is a different infinite moving average representation with uncorrelated shocks indexed by the orthogonal matrix $R$. Sims' identification strategy allows $R$ to belong to the class of permutation matrices, which is a subclass of orthogonal matrices. This procedure basically only allows to first reorder the variables in $x_{t}$ and then to apply the Choleski decomposition. There are $n$ ! different ways how to this, where $n$ is the number of variables entering the VAR.

Cooley and LeRoy (1985) criticized this recursive identification scheme to be atheoretical and claimed that a model identified by this arbitrary procedure cannot be interpreted as a structural model because a different variable ordering yields different structural parameters. Indeed, 
if $x_{t}$ contains more than two variables, it is rarely possible to postulate a recursive structure on the variables which is compatible with economic theory. As a reply to this criticism, Bernanke (1986), Blanchard and Watson (1986) and Sims (1986) introduced non-recursive restrictions on the contemporaneous interactions among variables for identification. As economic theory does often not provide enough meaningful contemporaneous restrictions, Blanchard and Quah (1989) introduced restrictions on the long-run properties of the system which are consistent with economic theory. In a system of real output growth and unemployment, they identified aggregate supply and demand shocks by restricting the latter to have no long-run impact on the level of real output. In general, to obtain identification, we need $n(n-1) / 2$ economically meaningful restrictions to identify the matrix $R$. To address the negative relation between inflation and real stock returns, Sims' recursive identification scheme has been applied by Lee (1992) and Balduzzi (1995). In line with the above criticism, their results do not really have a structural interpretation and are therefore difficult to interpret from an economic point of view. Economically meaningful identification of structural shocks is obtained in Hess and Lee (1999). They consider a bivariate system in real stock returns and inflation to identify supply and demand shocks driving those two variables. Following Blanchard and Quah (1989), they restrict demand shocks to have no long-run impact on real stock prices. They find that supply shocks induce a strong negative correlation between real stock returns and inflation, whereas demand shocks induce a slightly weaker but significant positive relation. Since supply shocks seem to be more important than demand shocks, the overall sign of the correlation between real stock returns and inflation is negative. Hess and Lee (1999) provide empirical evidence that demand shocks are mainly of monetary nature. They do not, however, attempt to identify monetary and non-monetary demand shocks in a formal structural model. Furthermore, they just concentrate on the relation between real stock returns and ex post inflation. They do not examine the "most puzzling result of all" (Schwert (1981), p. 28), namely the negative relation between ex ante real returns and ex ante inflation. Gallagher and Taylor (2002) essentially follow the same strategy as Hess and Lee (1999), but include real output growth in their system instead of real stock returns.

\section{Identification assumptions}

Since we treat a three variable system, we have to impose three restrictions on the system to identify the orthogonal matrix $R$. Following the pioneering work by Galí (1992) we use a combination of short- and long-run restrictions.

- A1-A2: To distinguish the AS shock from the two demand shocks, we assume that the latter have no long-run impact on the level of real stock prices. 
- A3: In order to separate real demand from monetary shocks we consider two alternatives ${ }^{3}$ :

- A3a: Real demand shocks have no short-run effect on inflation.

- A3b: The Fed's systematic behaviour can be characterized by a forward looking policy rule where the nominal interest rate responds positively to an increase in expected inflation.

A1 and A2 are long-run neutrality assumptions inspired by Blanchard and Quah (1989). The third restriction is of contemporaneous nature. The first alternative (A3a) is motivated by short-run price stickiness. The second alternative (A3b) is motivated by the fact that monetary policy can be well described by a forward-looking Taylor rule (see e.g. Boivin and Giannoni (2002)).

The long-run neutrality assumptions impose that the long-run multiplier matrix $\sum_{s=0}^{\infty}\left[A_{s} R\right]$ is restricted in the following way

$$
\text { A1-A2: } \quad\left[\sum_{s=0}^{\infty} C_{s} \tilde{\Omega}\right] R=\left[\begin{array}{ccc}
* & 0 & 0 \\
* & * & * \\
* & * & *
\end{array}\right] .
$$

The two alternatives of the short-run restriction are placed on the impact matrix of the structural shocks $\left(A_{0}\right)$ or the matrix of contemporaneous structural relations between the variables $\left(B_{0}\right)$, respectively. The first alternative means that the short-run effects of the structural shocks are restricted as:

$$
\text { A3a: } \quad A_{0}=\tilde{\Omega} R=\left[\begin{array}{ccc}
* & * & * \\
* & * & * \\
* & 0 & *
\end{array}\right]
$$

The second alternative is slightly more elaborate, it imposes the following restrictions on $B_{0}$ :

$$
\text { A3b: } \quad B_{0}=R^{\prime} \tilde{\Omega}^{-1}=\left[\begin{array}{ccc}
* & * & * \\
* & * & * \\
z_{1} & z_{2} & z_{2}\left(1-z_{3}\right)
\end{array}\right] \text {, }
$$

where $z_{1}$ and $z_{2}$ are arbitrary numbers and $z_{3}$ is a given positive number. Note that for period $t$, this implies the following short-run relationship between the variables in the model ${ }^{4}$ :

$$
i_{t}=-\frac{z_{1}}{z_{2}} \Delta s p_{t}^{e}+z_{3} \pi_{t}^{e}+\operatorname{lags}+u_{t}^{M M}
$$


The above equation can be interpreted as an empirical form of a forward looking Taylor-Rule implied by our VAR model. This assumption identifies the money market shock explicitly as the non-systematic or, more precisely, non-forecastable part of monetary policy. We require that the coefficient $z_{3}$ is positive, i.e. rising interest rates are the result of the Fed's reaction to increasing expected inflation. This assumption is fairly weak and does not impose strong behavioural assumptions on the Fed's monetary policy. In the empirical part of the paper we experiment with different positive values for $z_{3}$ and conclude that the results are very robust.

The restrictions (A1 - A3) together with $R R^{\prime}=I$ determine the orthogonal matrix $R$ and therefore identify our structural model ${ }^{5}$. As we do not see any a priori reason to favour A3a or $\mathrm{A} 3 \mathrm{~b}$ as the third identification restriction we will use both in the empirical part and refer to the corresponding identification schemes as version (a) and (b).

\section{Conditional covariance and correlation}

Assume that we have identified the system and obtained an estimate of the structural infinite moving average representation in (2.6). In the empirical part we will use the concepts of variance and covariance decomposition. Since the former is well known in the literature, e.g. Lee (1992), we concentrate in this section on the calculation of that part of the covariance between real stock returns and different components of inflation which is induced by a particular structural shock. Whereas the decomposition of variables which enter the VAR directly (inflation, real interest rate and real stock returns) is by now standard in the literature (e.g. Balduzzi (1995)), the decomposition of expected, unexpected and changes in expected components is novel. Although this novel decomposition is straightforward from a theoretical point of view, it is at the very heart of the subject considered in this article and allows us to establish new empirical results. To examine horizon effects, we develop this new decomposition over a general $h$-period horizon. To keep the discussion simple we develop results below for $h=1$ and leave the more involved general case to the appendix.

\section{D.1. Real stock returns and inflation}

Note that we can write the real stock return and inflation series as

$$
\begin{aligned}
\Delta s p_{t} & =\sum_{s=0}^{\infty} a_{11}(s) u_{t-s}^{A S}+\sum_{s=0}^{\infty} a_{12}(s) u_{t-s}^{R D}+\sum_{s=0}^{\infty} a_{13}(s) u_{t-s}^{M M}, \\
\pi_{t} & =\sum_{s=0}^{\infty} a_{31}(s) u_{t-s}^{A S}+\sum_{s=0}^{\infty} a_{32}(s) u_{t-s}^{R D}+\sum_{s=0}^{\infty} a_{33}(s) u_{t-s}^{M M},
\end{aligned}
$$


where $a_{i j}(s)$ denotes the entries in the matrix $A_{s}$ defined in (2.5). Since the structural shocks are mutually uncorrelated, the contemporaneous covariance between real stock returns and inflation is

$$
\begin{aligned}
\operatorname{Cov}\left(\Delta s p_{t}, \pi_{t}\right) & =\sum_{s=0}^{\infty} a_{11}(s) a_{31}(s)+\sum_{s=0}^{\infty} a_{12}(s) a_{32}(s)+\sum_{s=0}^{\infty} a_{13}(s) a_{33}(s) \\
& =\operatorname{Cov}_{A S}\left(\Delta s p_{t}, \pi_{t}\right)+\operatorname{Cov}_{R D}\left(\Delta s p_{t}, \pi_{t}\right)+\operatorname{Cov}_{M M}\left(\Delta s p_{t}, \pi_{t}\right) .
\end{aligned}
$$

This decomposition can easily be understood. For example, $\operatorname{Cov}_{A S}\left(\Delta s p_{t}, \pi_{t}\right)$ denotes that part of the covariance between real stock returns and inflation which is induced by aggregate supply shocks. This covariance decomposition allows us to calculate the intensity of the correlation between inflation and real stock returns (or other variables) according to the origin of the innovation. For example, the correlation between real stock returns and inflation induced by aggregate supply shocks is calculated as

$$
\varphi_{A S}\left(\Delta s p_{t}, \pi_{t}\right)=\frac{\operatorname{Cov}_{A S}\left(\Delta s p_{t}, \pi_{t}\right)}{\mathrm{SD}_{A S}\left(\Delta s p_{t}\right) \cdot \mathrm{SD}_{A S}\left(\pi_{t}\right)},
$$

where $S D_{A S}$ denotes the standard deviation of the aggregate supply component of the real stock return and inflation series respectively, where the former is calculated as

$$
\operatorname{SD}_{A S}\left(\Delta s p_{t}\right)=\left(\sum_{s=0}^{\infty}\left[a_{11}(s)\right]^{2}\right)^{1 / 2}
$$

Conditional correlations between other variables can be calculated in a similar way.

\section{D.2. Real stock returns and different inflation components}

First of all, we note that

$$
\begin{aligned}
\operatorname{Cov}\left(\Delta s p_{t}, \pi_{t}\right) & =\operatorname{Cov}\left(\Delta s p_{t}, \pi_{t}^{e}+\pi_{t}^{u}\right) \\
& =\operatorname{Cov}\left(\Delta s p_{t}, \pi_{t}^{e}\right)+\operatorname{Cov}\left(\Delta s p_{t}, \pi_{t}^{u}\right)
\end{aligned}
$$

Both covariance terms have been found to be negative in the literature as reported above. In the following, we propose a structural decomposition of these covariances into components driven 
by the various structural shocks. We first address the structural covariance decomposition between unexpected inflation and real stock returns. From (2.4) and (2.5),

$$
\begin{aligned}
\pi_{t}^{u} & =e_{3}^{\prime} \epsilon_{t}=e_{3}^{\prime} B_{0}^{-1} u_{t}=e_{3}^{\prime} A_{0} u_{t} \\
& =a_{31}(0) u_{t}^{A S}+a_{32}(0) u_{t}^{R D}+a_{33}(0) u_{t}^{M M}
\end{aligned}
$$

The covariance between real stock returns and unexpected inflation can therefore be written as

$$
\begin{aligned}
\operatorname{Cov}\left(\Delta s p_{t}, \pi_{t}^{u}\right) & =a_{11}(0) a_{31}(0)+a_{12}(0) a_{32}(0)+a_{13}(0) a_{33}(0) \\
& =\operatorname{Cov}_{A S}\left(\Delta s p_{t}, \pi_{t}^{u}\right)+\operatorname{Cov}_{R D}\left(\Delta s p_{t}, \pi_{t}^{u}\right)+\operatorname{Cov}_{M M}\left(\Delta s p_{t}, \pi_{t}^{u}\right) .
\end{aligned}
$$

The conditional correlation between these variables induced by the various structural shocks can be calculated as described in the previous subsection.

Similarly, the covariance decomposition between real stock returns and expected inflation can be calculated as

$$
\begin{aligned}
\operatorname{Cov}\left(\Delta s p_{t}, \pi_{t}^{e}\right) & =\sum_{s=1}^{\infty} a_{11}(s) a_{31}(s)+\sum_{s=1}^{\infty} a_{12}(s) a_{32}(s)+\sum_{s=1}^{\infty} a_{13}(s) a_{33}(s) \\
& =\operatorname{Cov}_{A S}\left(\Delta s p_{t}, \pi_{t}^{e}\right)+\operatorname{Cov}_{R D}\left(\Delta s p_{t}, \pi_{t}^{e}\right)+\operatorname{Cov}_{M M}\left(\Delta s p_{t}, \pi_{t}^{e}\right) .
\end{aligned}
$$

Finally, the last empirical puzzle, the negative relation between ex post real stock returns and changes in expected inflation can be decomposed into structural components writing

$$
\operatorname{Cov}\left(\Delta s p_{t}, \Delta \pi_{t+1}^{e}\right)=\sum_{s=0}^{\infty} a_{11}(s) a_{31}^{*}(s)+\sum_{s=0}^{\infty} a_{12}(s) a_{32}^{*}(s)+\sum_{s=0}^{\infty} a_{13}(s) a_{33}^{*}(s),
$$

where again the three sums denote the components attributable to the different structural shocks and

$$
a_{3 j}^{*}(s)=\left\{\begin{array}{cc}
a_{3 j}(1) & \text { if } s=0 \\
a_{3 j}(s+1)-a_{3 j}(s) & \text { if } s>0
\end{array}\right\} .
$$

The calculation of conditional correlations between the real interest rate and different inflation components induced by the various structural shocks follows the same lines. 


\section{Empirical results}

\section{A. The data}

For our empirical estimation, we use quarterly U.S. data from the first quarter of the year 1954 until the end of year 2003. The goods price level is the seasonally adjusted consumer price index (CPI) obtained from the Bureau of Labour Statistics. For stock prices we use the S\&P 500 index (Datastream). Finally, the nominal interest rate is the 3 month treasury bill rate obtained from the Board of Governors of the Federal Reserve System.

\section{B. Real stock returns, real rate of interest and inflation}

In this subsection we document the negative effect between real stock returns or the real interest rate and the different components of inflation. Compared to earlier work, we add around twenty years of data and measure the inflation components as described in Section I.A.

In a first step, we estimate the reduced form VAR (2.4) and extract directly from the VAR empirical proxies for (changes in) expected and unexpected inflation ${ }^{6}$.

Table I reports the inflation equation of the VAR system. In addition to past inflation rates, lags of the real interest rate have significant forecasting power for inflation. We therefore conclude that our multivariate approach adds significant information to measure expected inflation compared to a pure univariate time series approach.

In Table II we report different variants of the regression equation

$$
r_{j, t}=a_{0}+a_{1} \pi_{t}+a_{2} \pi_{t}^{e}+a_{3} \pi_{t}^{u}+a_{4} \Delta \pi_{t}^{e}+\epsilon_{t}
$$

These regressions are similar to those performed in Fama and Schwert (1977). We replace, however, their left hand variable, nominal asset returns, by real returns $r_{j, t}$, which are either real stock returns or the real interest rate. The $a_{2}$ coefficient measures the relationship between ex ante real asset returns and ex ante inflation. The 'Fisher hypothesis' implies that this coefficient should not be significantly different from zero. To obtain hypothesis about the $a_{3}$ coefficient, we must rely largely on intuition. Since the nominal value of Treasury Bills is fixed at maturity, the nominal return cannot react within the quarter to unexpected inflation which implies by construction a negative $a_{3}$ coefficient. This is not true for stock prices, whose nominal returns are not fixed in advance. It was generally believed in the seventies that stocks offer a complete hedge against unexpected inflation. The coefficient $a_{4}$ finally measures the 
sensitivity of real asset returns with respect to changes in expected inflation, whose influence has been examined for real stock returns. For details we refer to Fama and Schwert (1977).

Real stock returns and components of inflation Consistent with previous research, our sample and measuring method indicates that real stock returns are significantly negatively related to ex post inflation. The first regression in Table II shows that an increase in inflation of $1 \%$ is related to a contemporaneous decrease of $3.5 \%$ in real stock prices. The second regression indicates that both inflation components, expected and unexpected, are negatively correlated with real stock returns ${ }^{7}$. The negative impact of unexpected inflation on real stock returns is much larger than the impact of expected inflation. In fact, a $1 \%$ inflation surprise is related to a $6 \%$ drop in real stock prices, whereas anticipated inflation reduces them just by $2 \%$. Also, since our measures of expected and unexpected inflation are orthogonal by construction, we can conclude that $9 \%$ of the total $R^{2}$ of $13 \%$ come from the unexpected inflation component. Finally, the change in expected inflation, which is positively correlated with unexpected inflation (0.61), is also negatively related to real stock returns.

These results and the size of the coefficients are generally in line with earlier work by Nelson (1976), Fama and Schwert (1977) and Jaffe and Mandelker (1976) with the difference that we find that unexpected inflation has larger explanatory power than found in previous studies.

Real rate of interest and components of inflation Since the nominal return of a Treasury Bill is fixed in advance as described earlier on, it should come at no surprise that inflation is negatively related to the real interest rate. Table II shows, however, that it is not only unexpected inflation which induces this negative correlation, but also expected inflation, which is in sharp contradiction to the 'Fisher hypothesis'. Again, since our measures of ex ante and surprise inflation are orthogonal, we can conclude that the $R^{2}$ in this regression can be decomposed into $6 \%$ coming from the expected inflation component and $39 \%$ from the unexpected component.

\section{Impulse response function}

In this subsection we discuss the impulse response function for the different identification schemes discussed in Section I.C. Figure 1 plots the impulse response functions when restriction A3a is used to separate the two demand shocks. We note that this short-run restriction completely identifies our structural VAR model. Therefore, it allows us to determine an empirical value of $z_{3}$ in restriction A3b. This value turns out to be positive, as it is reasonable, and 
close to four. This leads us to experiment with values for $z_{3}$ equal to 1,4 and 10 to examine the robustness of the results resulting from the identifying restriction A3b. Since the impulse response for these different versions are qualitatively and quantitatively almost identical, we report in Figure 2 just the plots for the intermediate version ${ }^{8}$. Confidence bands for all impulse response functions are based on the bootstrap procedure described in Kilian $(1998)^{9}$.

Comparing Figures 1 and 2, it is apparent that the two different identification strategies (a) and (b) yield almost the same results. Therefore, our results are, at least visually, robust with respect to the two different identification strategies.

Aggregate supply shocks Real stock prices show a significantly positive response to AS shocks on impact. The price level drops significantly due to the AS shock and then slowly approaches its new level over several quarters. Furthermore, the effect on the real interest rate is positive and significant on impact and just turns insignificant after approximately two years.

Real demand shocks RD shocks slightly increase real stock prices but have no significant effect on them. The RD shock has a positive effect on the price level. Note that the effect of this shock on the price level is restricted to be zero on impact. It is encouraging to see that this restriction seems not to be harsh, since the impulse response function for version (b), which does not rely on short-term price stickiness, produces an almost identical picture ${ }^{10}$. Finally, the effect of the RD shock on the real rate of interest is initially positive but then decreases again and has no long-run impact.

Money market shocks The MM shock has a positive and significant effect on real stock prices on impact but vanishes after several quarters. Note that this somewhat puzzling dynamics concern real stock prices. The impulse response function for the nominal stock price (not shown) increases on impact and thereafter remains on a permanently higher level. It is the gradually increasing price level which brings back real stock prices to their initial level. The initial real effect on stock prices of the MM shock is smaller than the effect of the AS shock. The real rate of interest shows a significant 'text book' liquidity effect caused by the MM shock and then slowly returns to its original level. These dynamics induced by the MM shock are exactly what one expects to see from a properly identified money shock. 


\section{C.1. Structural decomposition and conditional correlations}

In this subsection we discuss the structural decomposition of real stock returns, the real interest rate and different components of inflation into subseries driven by AS, RD or MM shocks. Time series plots of these subseries are reported in Figure 3 and scatter plots illustrating the relation between the return variables and different structural components of inflation can be found in Figure 4. To save space, these graphs are just reported for identification version (b). Again results for version (a) are very similar. Tables III and IV report for both identification schemes the conditional correlations between structural components of the real stock return (or the real rate of interest) and different components of inflation as discussed in Section I.D. The analysis is carried out for various time horizons. Confidence intervals for the conditional correlations are based on the bootstrap procedure described in Kilian $(1998)^{11}$. The variance decomposition is reported in Table $\mathrm{V}$ for both identification versions.

Real stock returns and components of inflation The variance decomposition in Table $\mathrm{V}$ and the time series plots of the structural decomposition in Figure 3 indicate that the AS shock is the most important shock for the dynamics of real stock prices. Whereas the monetary shock also plays a role for the short-run dynamics of stock prices, the RD shock is largely unimportant. Furthermore, AS and MM shocks are also the most important shocks for short- and long-run dynamics of the price level which implies that the correlation between real stock returns and inflation is mainly driven by AS and MM shocks. In Figure 3, note that the two oil price shocks in the mid and late 70's are clearly visible in the AS part of inflation ${ }^{12}$. Furthermore, there is an apparent shift in the monetary component of inflation around 1980 related to the change in the Fed's monetary policy operating procedure. These observations empirically validate our economically motivated identification procedure.

We turn next to the conditional correlations between real stock returns and different inflation components over a quarterly horizon. In Section II.B we found that unexpected inflation had a stronger negative impact on real stock returns than expected inflation and explained a larger fraction of their variance. For real stock returns and both, ex post and unexpected inflation, Tables III and IV report that the sign of the conditional correlation depends on the economic source of the shock. The AS shock induces a strong negative correlation between real stock returns and both inflation components. If the AS shock enters through the unexpected inflation component, then the shock brings positive news for present and future output growth which through discounting increases real stock prices immediately. This strongly supports the proxy hypothesis of Fama (1981). The conditional correlation between real stock returns and inflation induced by the MM shock is positive but largely insignificant. However, 
it turns significant in version (b) for the unexpected inflation component. These empirical results are consistent with Danthine and Donaldson (1986) and Marshall (1992). The overall negative relation between real stock returns and inflation results because real shocks are more important for the interdependence of those series than monetary shocks. The negative relation between AS components of real stock returns and inflation and the corresponding positive relation for the MM components has also been found by Hess and Lee (1999) in a bivariate VAR, distinguishing supply and demand shocks only.

Looking at the relation between real stock returns and expected inflation, we find that the correlation between these series is negative, independently of the identifying assumptions, and whatever the economic source of the shock is. Furthermore this effect is always significant for the AS and MM shocks. The AS shock which is the main driving force pushes inflation expectations downwards whereas return expectations for real stocks are increased. The AS shock therefore induces a negative correlation between real stock returns and expected inflation.

Note that, conditioned on real supply shocks, the signs of correlation between real stock returns, expected and unexpected inflation coincide. The opposite is true for the MM shock. Once the monetary shock occurred and temporarily increased real stock prices, the effect is reversed and leads to negative expected real stock returns. Expected inflation is, however, pushed upwards which yields a negative correlation between ex ante real stock returns and expected inflation. The variance decomposition indicates that this negative correlation is less important than the one induced by the AS shock. These findings are therefore consistent with the predictions of Marshall (1992).

Turning to longer horizons, Tables III and IV show that the results are qualitatively similar to those over a quarterly horizon. Note that empirical results for all horizons are recovered from the same quarterly VAR model. Estimating VAR models over different horizons is not a valid alternative, since e.g. the identification assumption of short-run price stickiness becomes questionable once longer horizons than a quarter are considered. Boudoukh and Richardson (1993) find stronger support for the Fisher hypothesis, when considering longer horizons. Note that the relation between real stock returns and ex ante inflation is the relevant concept to analyze this issue. Tables III and IV report that for both, AS and MM shocks, the negative conditional correlation decreases in absolute value with the horizon, however, it remains significant.

Real interest rate and components of inflation The variance decomposition in Table V and the structural decomposition of inflation and the real rate of interest in Figure 3 indicate that the AS and MM shocks are the most important sources for both, short and long-run 
dynamics of inflation and the real interest rate. We are especially interested in the relation between the real interest rate and ex ante inflation, which is the relevant measure of inflation to examine the validity of the Fisher hypothesis. Analyzing quarterly results, for both, the AS and the MM shock, the conditional correlation between the real interest rate and expected inflation is negative. However, the reasons why this happens are different.

Concerning the AS shock which is assumed to have permanent effects on real activity ${ }^{13}$, Figure 1 shows that the real interest rate is increasing on impact whereas the price level drops. This observation favours the procyclical money demand argument of Fama and Gibbons (1982). The raise in the real rate of interest following an AS shock permits to guess that the expected real rate of interest and expected real activity are positively correlated, which is again in line with Fama and Gibbons (1982), but contradicts the Mundell-Tobin model.

For the MM shock, the findings are reversed. Due to price stickiness, the MM shock does not only influence the real interest rate on impact but also increases expected inflation which leads to a decrease in the expected real rate of interest. This is the textbook liquidity effect which is followed by a (short term) boom in investment and real activity, we refer to Galí (1992) for a more detailed discussion. In a nutshell, this is empirical evidence in favour of the Mundell-Tobin model, but contradicts Fama and Gibbons (1982) since the expected real interest rate is negatively correlated with expected real activity.

We can therefore conclude that the validity of the arguments of Fama and Gibbons against those of Mundell and Tobin depends on whether the negative correlation between the real interest rate is induced by an AS or MM shock. The results presented in this section indicate that both explanations are important and significant over a quarterly horizon. Once we consider longer horizons, however, both negative conditional correlations decrease in absolute value and become very small and insignificant at the annual horizon. So, although the Fisher hypothesis does not hold in the short term, the negative correlation between the real interest rate and expected inflation induced by AS and MM shocks dissappears over longer horizons.

\section{C.2. Subperiod analysis}

As discussed in the previous section, there appears to be a change in the monetary component of inflation around 1980 induced by the change in the Fed's operating procedure. In fact, Kaul (1990) reports that the negative relation between real stock returns and inflation is not stable after the post-World War II period and argues that the interest rate regime adopted before 1979Q3 produced a stronger negative correlation than the following money supply regime. In 
a previous study, Gallagher and Taylor (2002) confirm this empirical observation in a two variable VAR framework.

Note that the identification assumptions we use to disentangle demand shocks into real and monetary components are fairly mild and can easily be justified for the whole sample period. Nevertheless, it is interesting to apply our procedure separately to the periods 1954Q1 - 1979Q3 and 1979Q4 - 2003Q4. We estimated two separate VAR models and applied the same identification scheme as discussed previously. A word of caution applies here in interpreting results for the first subperiod ranging from 1954Q1 till 1979Q3. Although inflation appears stationary over the whole sample period, a unit root in inflation cannot be rejected for the first subperiod by both, the $\mathrm{ADF}$ and the $\mathrm{PP}$ tests ${ }^{14}$. We therefore restrict our analysis mainly to the second subperiod ranging from 1979Q4 till 2003Q4. Table VI reports that the AS shock still induces a negative correlation between real stock returns and all different components of inflation. The effect is, however, no longer significant when entering through ex ante inflation. The conditional correlation between real stock returns and unexpected (expected) inflation induced by the MM shock is still positive (negative) but no longer significant. For the real rate of interest and expected inflation, the MM shock still induces a weak and marginally significant negative conditional correlation. Note that only the MM part of the inflation surprise induces a significant negative correlation between the real interest rate and unexpected inflation. The negative effect of the AS shock disappears over the near past and the story of Fama and Gibbons seems therefore to be no longer of importance nowadays. The fact that most conditional correlations, although similar in sign, are no longer significant has two reasons: A decreased sample size (implying larger confidence intervals) and a decreasing effect of structural shocks on the economy as exemplified by Figure 5 which plots the impulse response function for the second subperiod. The effect of AS shocks on the price level have decreased since the Fed seems to accommodate these shocks nowadays and no longer leaves money largely fixed as suggested in Fama (1981). The price level is mainly moved by MM and RD shocks. Note that AS and MM shocks are still important for the dynamics of the real interest rate. This decreasing effect of structural shocks on the economy in the near past is consistent with the analysis in Boivin and Giannoni (2002).

\section{Summary}

In this paper we examined the negative correlation of real stock returns and the real interest rate with different components of inflation over several time horizons within the same structural framework. We applied a reduced form VAR to get estimates of expected and unexpected inflation. In a second step, we used the structural form of the VAR to decompose these series 
into parts driven by aggregate supply, real demand and money market shocks. Concerning the relation between real stock returns and unexpected inflation, we find strong evidence for the 'proxy hypothesis' brought forward by Fama (1981). Also, the sign of the correlation between real stock returns and (unexpected) inflation depends on the origin of the shock. It is negative for aggregate supply and real demand shocks, but positive for monetary shocks. This is consistent with Danthine and Donaldson (1984), Marshall (1992) and confirms earlier research by Hess and Lee (1999) who consider the relation between real stock returns and ex post inflation. Furthermore, we also find that the negative correlation between expected real stock returns and expected inflation is independent of the origin of the structural shock. This is largely consistent with Marshall (1992).

Concerning the negative relation between the real interest rate and inflation, we provide evidence that the two mainstream explanations of this empirical feature can both be supported by the data. The explanation of Fama and Gibbons (1982) can be supported when the negative correlation between the real rate of interest and inflation is induced by an aggregate supply shock. The Mundell-Tobin model yields the right answer when a money market shock is at work.

Our analysis also shows that both, the negative correlation between real stock returns or the real interest rate and inflation has decreased from the 80's onwards, mainly because of a decreasing effect of structural shocks on the real economy. 


\section{Appendix}

In this section we develop the structural decomposition proposed in Section 2.4 for a general time horizon $h$. Note first that

$$
\pi_{t+j}=\sum_{s=0}^{\infty} a_{31}(s) u_{t+j-s}^{A S}+\sum_{s=0}^{\infty} a_{32}(s) u_{t+j-s}^{R D}+\sum_{s=0}^{\infty} a_{33}(s) u_{t+j-s}^{M M} .
$$

Total inflation over periods $t+1$ till $t+h$ can therefore be written as

$$
\begin{aligned}
\pi_{t+1, t+h} & =\sum_{j=1}^{h} \pi_{t+j} \\
& =\sum_{j=1}^{h}\left(\sum_{s=0}^{\infty} a_{31}(s) u_{t+j-s}^{A S}+\sum_{s=0}^{\infty} a_{32}(s) u_{t+j-s}^{R D}+\sum_{s=0}^{\infty} a_{33}(s) u_{t+j-s}^{M M}\right) \\
& =\pi_{t+1, t+h}^{A S}+\pi_{t+1, t+h}^{R D}+\pi_{t+1, t+h}^{M M} .
\end{aligned}
$$

We will now develop the expression for the expected part of inflation, the unexpected part is then just the difference between the full inflation component and its expected part. For this purpose, note that

$$
\begin{aligned}
\pi_{t+j}= & \sum_{s=0}^{j-1} a_{31}(s) u_{t+j-s}^{A S}+\sum_{s=0}^{j-1} a_{32}(s) u_{t+j-s}^{R D}+\sum_{s=0}^{j-1} a_{33}(s) u_{t+j-s}^{M M} \\
& +\sum_{s=j}^{\infty} a_{31}(s) u_{t+j-s}^{A S}+\sum_{s=j}^{\infty} a_{32}(s) u_{t+j-s}^{R D}+\sum_{s=j}^{\infty} a_{33}(s) u_{t+j-s}^{M M} .
\end{aligned}
$$

Therefore, the expected period $t+j$ inflation given information at time $t$ is given by

$$
\pi_{t+j \mid t}^{e}=\sum_{s=j}^{\infty} a_{31}(s) u_{t+j-s}^{A S}+\sum_{s=j}^{\infty} a_{32}(s) u_{t+j-s}^{R D}+\sum_{s=j}^{\infty} a_{33}(s) u_{t+j-s}^{M S} .
$$

Total expected inflation for period $t+1$ till $t+h$ given information at time $t$ is therefore given by

$$
\begin{aligned}
\pi_{t+1, t+h \mid t}^{e} & =\sum_{j=1}^{h} \pi_{t+j \mid t}^{e} \\
& =\sum_{j=1}^{h}\left(\sum_{s=j}^{\infty} a_{31}(s) u_{t+j-s}^{A S}+\sum_{s=j}^{\infty} a_{32}(s) u_{t+j-s}^{R D}+\sum_{s=j}^{\infty} a_{33}(s) u_{t+j-s}^{M M}\right) \\
& =\pi_{t+1, t+h \mid t}^{e, A S}+\pi_{t+1, t+h \mid t}^{e, R D}+\pi_{t+1, t+h \mid t}^{e, M M},
\end{aligned}
$$


using obvious notation. The unexpected inflation component driven by e.g. the AS shock is simply given by

$$
\pi_{t+1, t+h \mid t}^{u, A S}=\pi_{t+1, t+h}^{A S}-\pi_{t+1, t+h \mid t}^{e, A S} .
$$

Based on these results, conditional correlations can then be calculated as presented in Section 2.4 .

\section{Acknowledgements}

The first author gratefully acknowledges financial support from the Swiss National Science Foundation through the National Centre of Competence in Research: Financial Valuation and Risk Management (NCCR-FINRISK). We also would like to thank G. Connor, J. P. Danthine, P. de Goeij, D. Hoechle, P. Kugler, Y. Lengwiler, O. Linton, A. Patton, M. Rockinger, O. Scaillet, R. Stulz and participants at the FMG seminar at the LSE, the 2004 Swiss Doctoral Workshop in Finance in Gerzensee, and the 2004 EFMA Meeting in Basel for helpful comments. Part of this research has been done while the first author was visiting the LSE. 


\section{References}

Amisano, G. and C. Giannini, 1997, "Topics in Structural VAR Econometrics," SpringerVerlag.

Balduzzi, P., 1995, "Stock Returns, Inflation, and the 'Proxy Hypothesis': A New Look at the Data," Economics Letters, 48, 47-53.

Bernanke, B. S., 1986, "Alternative Explanations of the Money-Income Correlation," CarnegieRochester Conference Series on Public Policy, 25, 49-100.

Blanchard, O. J. and D. Quah, 1989, "The Dynamic Effects of Aggregate Demand and Supply Disturbances," The American Economic Review, 79, 655-673.

Blanchard, O. J. and M. Watson, 1986, "Are Business Cycles all Alike?," In R. Gordon (ed.), The American Business Cycle, NBER and University of Chicago Press, 123-156.

Bodie, Z., 1976, "Common Stocks as a Hedge against Inflation," The Journal of Finance, 31, 459-470.

Boivin, J. and M. Giannoni, 2002, "Has Monetary Policy Become Less Powerful?," Working Paper, Federal Reserve Bank of New York.

Boudoukh, J. and M. Richardson, 1993, "Stock Returns and Inflation: A Long-Horizon Perspective," The American Economic Review, 83, 1346-1355.

Cooley, T. F. and S. F. LeRoy, 1985, "Atheoretical Macroeconomics: A Critique," The Journal of Monetary Economics, 16, 283-308.

Danthine, J. P. and J. Donaldson, 1986, "Inflation and Asset Prices in an Exchange Economy," Econometrica, 54, 585-606.

Day, T. E., 1984, "Real Stock Returns and Inflation," The Journal of Finance, 39, 493-502.

Fama, E. F., 1975, "Short Term Interest Rates as Predictors of Inflation," American Economic Review, 65, 269-282.

Fama, E. F. and G. W. Schwert, 1977, "Asset Returns and Inflation," The Journal of Financial Economics, 5, 115-146.

Fama, E. F., 1981, "Stock Returns, Real Activity, Inflation and Money," The American Economic Review, 71, 545-565.

Fama, E. F. and M. R. Gibbons, 1982, "Inflation, Real Returns and Capital Investments," The Journal of Monetary Economics, 239-258.

Fama, E. F., 1983, "Stock Returns, Real Activity, Inflation and Money: Reply," American Economic Review, 73, 471-472. 
Galí, J., 1992, "How Well Does the IS-LM Model Fit Postwar U.S. Data?," The Quarterly Journal of Economics, 107, 709-738.

Gallagher, L. A. and M. P. Taylor, 2002, "The Stock Return - Inflation Puzzle Revisited", Economics Letters, 75, 147-156.

Geske, R. and R. Roll, 1983, "The Monetary and Fiscal Linkage between Stock Returns and Inflation," The Journal of Finance, 38, 1-33.

Hess, P. J. and B. S. Lee, 1999, "Stock Returns and Inflation with Supply and Demand Disturbances", The Review of Financial Studies, 12, 1203-1218.

Jaffe, J. F. and G. Mandelker, 1976, "The 'Fisher Effect' for Risky Assets: An Empirical Investigation," The Journal of Finance, 31, 447-458.

James, Ch., Koreisha, S. and M. Partch, 1985, " A VARMA Analysis of the Causal Relations among Stock Returns, Real Output, and Nominal Interest Rates," The Journal of Finance, 40, 1375-1384.

Kaul, G., 1990, "Monetary Regimes and the Relation between Stock Returns and Inflationary Expectations," The Journal of Financial and Quantitative Analysis, 25, 307-321.

Kilian, L., 1998, "Small-Sample Confidence Intervals for Impulse Response Functions," The Review of Economics and Statistics, 80, 218-230.

Lee, B. S., 1992, "Causal Relations Among Stock Returns, Interest Rates, Real Activity and Inflation," The Journal of Finance, 47, 1591-1603.

Lee, B.S., 2003, "Asset Returns and Inflation in Response to Supply, Monetary, and Fiscal Disturbances," Review of Quantitative Finance and Accounting, 21, 207-231.

Lintner, J., 1975, "Inflation and Security Return," The Journal of Finance, 30, 259-280.

Marshall, D. A., 1992, "Inflation and Asset Returns in a Monetary Economy," The Journal of Finance, 47, 1315-1342.

Mundell, R., 1963, "Inflation and Real Interest," Journal of Political Economy, 71, 280-283.

Nelson, C. R., 1976, "Inflation and Rates of Return on Common Stocks," The Journal of Finance, 31, 471-483.

Schwert, G. W., 1981, "The Adjustment of Stock Prices to Information about Inflation," The Journal of Finance, 36, 15-29.

Sims, C. A., 1980, "Macroeconomics and Reality," Econometrica, 48, 1-48.

Sims, C. A., 1986, "Are Forecasting Models usable for policy Analysis?" Federal Reserve Bank of Minneapolis, Quarterly Review, 2-16. 
Solnik, B., 1983, "The Relation between Stock Prices and Inflationary Expectations: The International Evidence," The Journal of Finance, 38, 35-48.

Stulz, R. M.,1986, "Asset Pricing and Expected Inflation," The Journal of Finance, 41, 209223.

Tobin, J., 1965, "Money and Economic Growth," Econometrica, 33, 671-684. 


\section{Notes}

${ }^{1}$ An exception is Lee (2003) who discusses a similar VAR system like the one in this paper. However, his identification scheme is flawed since he puts a long-run restriction on a stationary variable.

${ }^{2}$ We assume that the mean of the variables has previously been subtracted. We therefore do not specify a constant term in the VAR.

${ }^{3}$ We note that these different alternatives will just influence empirical results concerning the qualitative and quantitative effects of the two demand shocks. All empirical results concerning the AS shock will be identical across the different identification schemes.

${ }^{4}$ The structural vector autoregressive representation and (2.7) imply that $e_{3}^{\prime} B_{0} x_{t}$ can be written as

$$
i_{t}=-\frac{z_{1}}{z_{2}} \Delta s p_{t}+z_{3} \pi_{t}+\operatorname{lags}+u_{t}^{M M} .
$$

Recall that $i_{t}$ is determined at the beginning of the period, when stock market returns and inflation are not known yet. Taking the conditional expectation on past information of the above equation and noting that the Fed has some scope in setting the interest rate by choosing $u_{t}^{M M}$ yields the forward looking Taylor rule in (2.8).

${ }^{5}$ For a technical reference on shock identification and computational issues around SVAR models, we refer to Amisano and Giannini (1997).

${ }^{6}$ Standard lag length criteria (AIC, SC and HQ) returned an optimal lag length of two for the VAR model which was imposed throughout the analysis.

${ }^{7}$ Note that our proxies for expected and unexpected inflation are subject to measurement error. Since both components are orthogonal, we can say that the coefficients we obtain are biased towards zero.

${ }^{8}$ An additional appendix with empirical results for all different identification schemes can be obtained from the authors on request.

${ }^{9}$ We note that other authors mentioned in the introduction do not report confidence bands for the impulse response functions. The statistical significance of their results is therefore hard to assess.

${ }^{10}$ We note that it would be possible to impose all of the identifying restrictions A1, A2, A3a and $\mathrm{A} 3 \mathrm{~b}$ at the same time. This would allow us to test the overidentifying restrictions. We do 
not pursue this here any further, since both identification strategies, A3a and A3b, produce almost identical results, which makes a formal test obsolete.

${ }^{11}$ We note that this bootstrap procedure to compute confidence intervals is especially important in this context since the usual standard errors unadjusted for the first step estimation of structural components are way to small.

${ }^{12}$ Oil shocks are best understood as AS shocks, since oil was at least at this time a very important input for the aggregate production function.

${ }^{13}$ We note that real output is not directly in the VAR considered in this paper. However, it is well known that AS shocks have permanent effects on real output, whereas MM shocks have short term but significant effects on real output. We refer to Galí (1992) for a detailed discussion of these effects.

${ }^{14}$ This is a problem commonly encountered in a time series context. It is well known that to adequately determine stationarity of a series, the length of the sample period is of central importance and results can differ considering different subsamples. 
TABLE I: Parameter Estimates of the Inflation Equation in the VAR Model

This table provides ordinary least squares parameter estimates of the inflation equation of a vector autoregressive model containing the variables real stock returns $\left(\Delta s p_{t}\right)$, the real interest rate $\left(i_{t}-\pi_{t}\right)$, and inflation $\left(\pi_{t}\right)$. The estimation period is 1954Q1 till 2003Q4 and values in brackets indicate t-statistics.

\begin{tabular}{crrrr} 
& \multicolumn{1}{c}{$c$} & $\Delta s p_{t-1}$ & $(i-\pi)_{t-1}$ & $\pi_{t-1}$ \\
& & $\Delta s p_{t-2}$ & $(i-\pi)_{t-2}$ & $\pi_{t-2}$ \\
\hline \multirow{2}{*}{$\pi_{t}$} & 0.35 & -0.004 & 0.92 & 1.23 \\
& {$[1.22]$} & {$[-1.00]$} & {$[6.58]$} & {$[9.18]$} \\
& & & & \\
& & & & \\
& & {$[1.004$} & -0.82 & -0.36 \\
& & {$[-5.91]$} & {$[-2.66]$} \\
& & & \multicolumn{3}{c}{$R^{2}=0.69$}
\end{tabular}


TABLE II: Real Stock Returns, Real Interest Rate and Inflation Components

This table provides ordinary least squares estimates of different variants of the regression equation

$$
r_{j, t}=a_{0}+a_{1} \pi_{t}+a_{2} \pi_{t}^{e}+a_{3} \pi_{t}^{u}+a_{4} \Delta \pi_{t}^{e}+\epsilon_{t} .
$$

Real asset returns $\left(r_{j, t}\right)$ are either given by real stock returns $\left(\Delta s p_{t}\right)$ or the real interest rate $\left(i_{t}-\pi_{t}\right)$. Inflation is denoted by $\pi_{t}$, and $\pi_{t}^{e}$ and $\pi_{t}^{u}$ are the expected and unexpected component of inflation. Finally $\Delta \pi_{t}^{e}$ denotes the change in expected inflation. The estimation period is 1954Q1 till 2003Q4, and values in brackets indicate t-statistics.

\begin{tabular}{|c|c|c|c|c|c|}
\hline$r$ & $a_{0}$ & $\pi$ & $\pi^{e}$ & $\pi^{u}$ & $\Delta \pi^{e}$ \\
\hline \multirow[t]{2}{*}{$\Delta s p$} & $\begin{array}{r}17.12 \\
{[4.93]}\end{array}$ & $\begin{array}{l}-3.47 \\
{[-4.99]}\end{array}$ & & & \\
\hline & & & & & $R^{2}=0.11$ \\
\hline \multirow[t]{2}{*}{$\Delta s p$} & $\begin{array}{r}12.52 \\
{[3.19]}\end{array}$ & & $\begin{array}{l}-2.32 \\
{[-2.79]}\end{array}$ & $\begin{array}{l}-5.85 \\
{[-4.67]}\end{array}$ & \\
\hline & & & & & $R^{2}=0.13$ \\
\hline \multirow[t]{2}{*}{$\Delta s p$} & $\begin{array}{r}3.27 \\
{[1.43]}\end{array}$ & & & & $\begin{array}{l}-5.54 \\
{[-3.26]}\end{array}$ \\
\hline & & & & & $R^{2}=0.05$ \\
\hline \multirow[t]{2}{*}{$(i-\pi)$} & $\begin{array}{c}2.21 \\
{[9.70]}\end{array}$ & & $\begin{array}{l}-0.20 \\
{[-4.18]}\end{array}$ & $\begin{array}{r}-0.86 \\
{[-11.77]}\end{array}$ & \\
\hline & & & & & $R^{2}=0.45$ \\
\hline
\end{tabular}




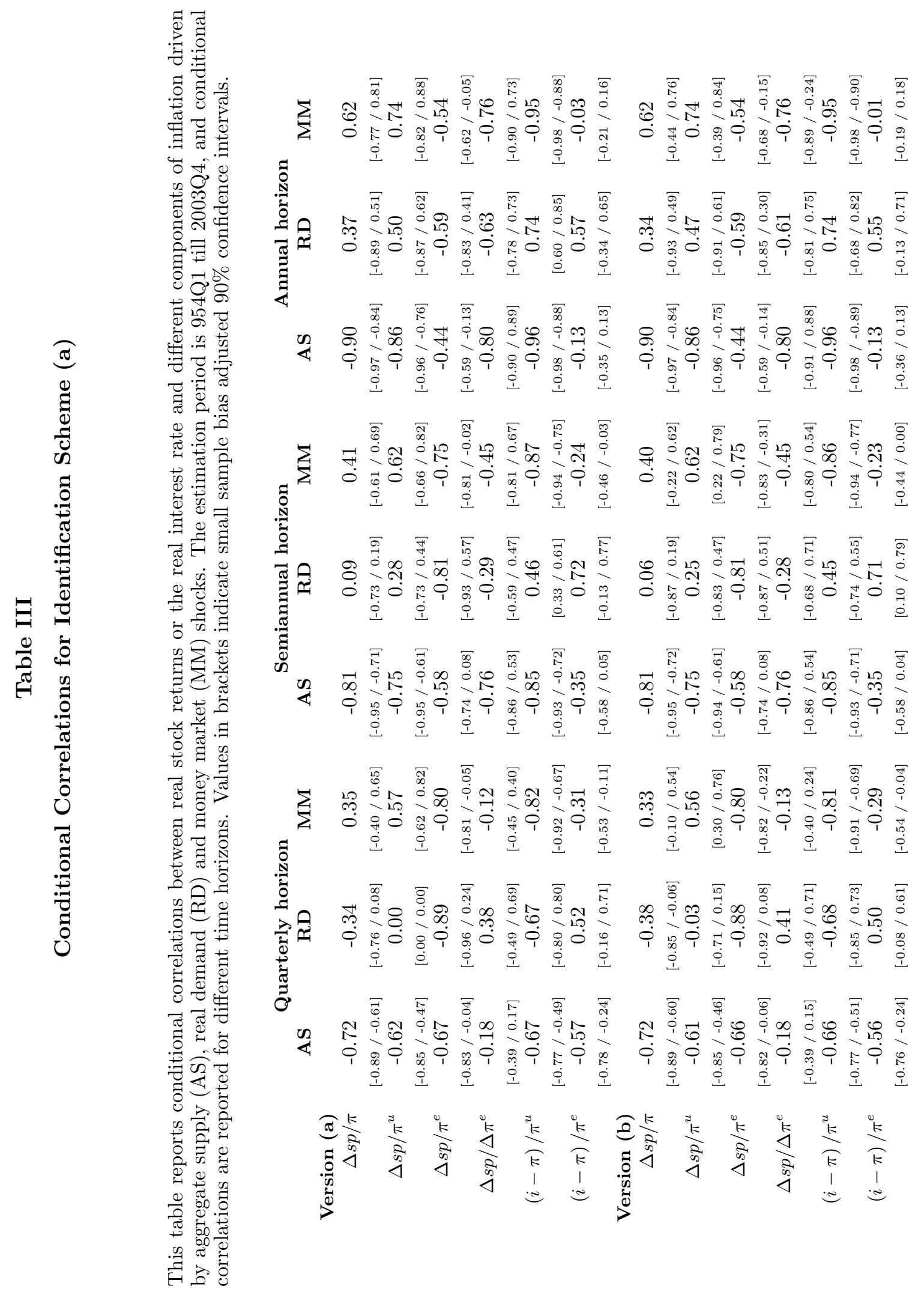




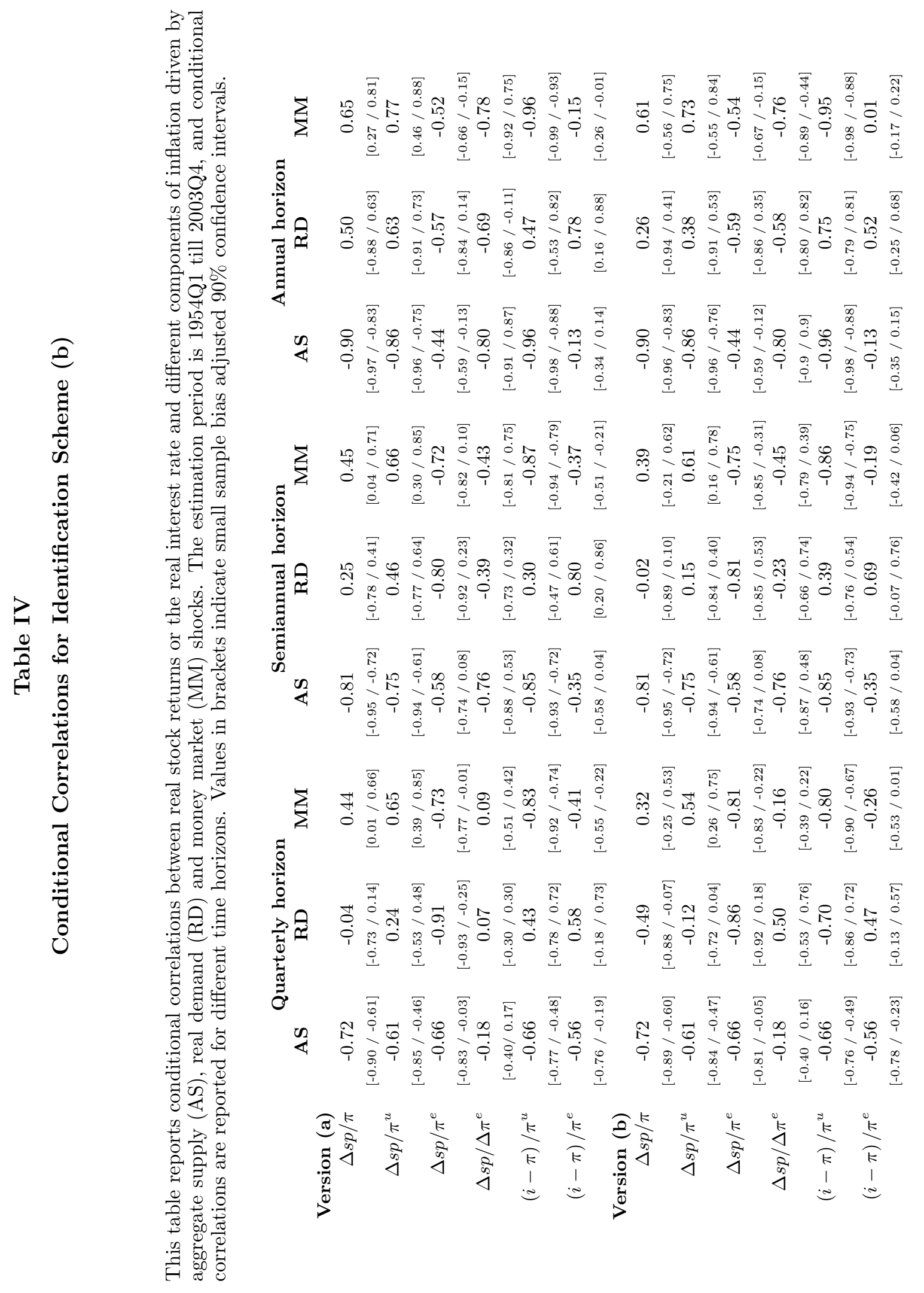


TABle V: Variance Decomposition for Real Stock Returns, Inflation and Real Interest Rate

This table reports the variance decomposition (associated with aggregate supply (AS), real demand (RD) and money market (MM) shocks) for real stock returns, inflation, and the real interest rate. The estimation period is 1954Q1 till 2003Q4, and results are reported for both identification schemes, (a) and (b).

\begin{tabular}{|c|c|c|c|c|c|}
\hline \multicolumn{6}{|c|}{ Real Stock Returns } \\
\hline Quarter & AS & $\mathrm{RD}(\mathrm{a})$ & MM (a) & RD (b) & MM (b) \\
\hline 1 & 72.9 & 2.8 & 24.3 & 3.4 & 23.7 \\
\hline 2 & 77.2 & 1.8 & 21.0 & 2.2 & 20.6 \\
\hline 3 & 80.0 & 1.4 & 18.6 & 1.7 & 18.3 \\
\hline 4 & 82.5 & 1.2 & 16.3 & 1.5 & 16.0 \\
\hline 8 & 89.2 & 0.6 & 10.2 & 0.8 & 10.0 \\
\hline 12 & 92.8 & 0.4 & 6.8 & 0.5 & 6.7 \\
\hline 16 & 94.8 & 0.3 & 4.9 & 0.4 & 4.9 \\
\hline 20 & 96.0 & 0.2 & 3.8 & 0.3 & 3.7 \\
\hline 24 & 96.8 & 0.2 & 3.1 & 0.2 & 3.0 \\
\hline \multicolumn{6}{|c|}{ Inflation } \\
\hline Quarter & AS & RD (a) & MM (a) & RD (b) & MM (b) \\
\hline 1 & 56.3 & 0.1 & 43.7 & 0.0 & 43.7 \\
\hline 2 & 60.2 & 4.6 & 35.2 & 5.3 & 34.6 \\
\hline 3 & 57.7 & 5.6 & 36.7 & 6.5 & 35.8 \\
\hline 4 & 54.5 & 6.7 & 38.8 & 7.7 & 37.8 \\
\hline 8 & 49.2 & 8.8 & 42.1 & 10.0 & 40.8 \\
\hline 12 & 47.1 & 9.4 & 43.4 & 10.8 & 42.1 \\
\hline 16 & 46.2 & 9.7 & 44.1 & 11.1 & 42.7 \\
\hline 20 & 45.7 & 9.8 & 44.6 & 11.2 & 43.2 \\
\hline 24 & 45.4 & 9.8 & 44.8 & 11.2 & 43.4 \\
\hline \multicolumn{6}{|c|}{ Real Interest Rate } \\
\hline Quarter & AS & RD (a) & MM (a) & RD (b) & MM (b) \\
\hline 1 & 34.7 & 25.0 & 40.2 & 23.0 & 42.3 \\
\hline 2 & 43.2 & 20.7 & 36.1 & 19.0 & 37.8 \\
\hline 3 & 44.2 & 21.4 & 34.4 & 19.7 & 36.1 \\
\hline 4 & 44.0 & 21.2 & 34.8 & 19.5 & 36.5 \\
\hline 8 & 43.6 & 23.7 & 32.7 & 22.0 & 34.4 \\
\hline 12 & 42.3 & 26.1 & 31.6 & 24.4 & 33.2 \\
\hline 16 & 41.4 & 27.3 & 31.3 & 25.8 & 32.8 \\
\hline 20 & 40.9 & 27.8 & 31.3 & 26.4 & 32.8 \\
\hline 24 & 40.6 & 27.9 & 31.5 & 26.6 & 32.8 \\
\hline
\end{tabular}


TABLE VI: Conditional Correlations in Subperiods

This table reports conditional correlations for subperiods of the full sample between real stock returns or the real interest rate and different components of inflation driven by aggregate supply (AS), real demand (RD) and money market (MM) shocks. The first estimation period is 1954Q1 till 1979Q3, and the second subperiod 1979Q4 till 2003Q4. Values in brackets indicate small sample bias adjusted 90\% confidence intervals.

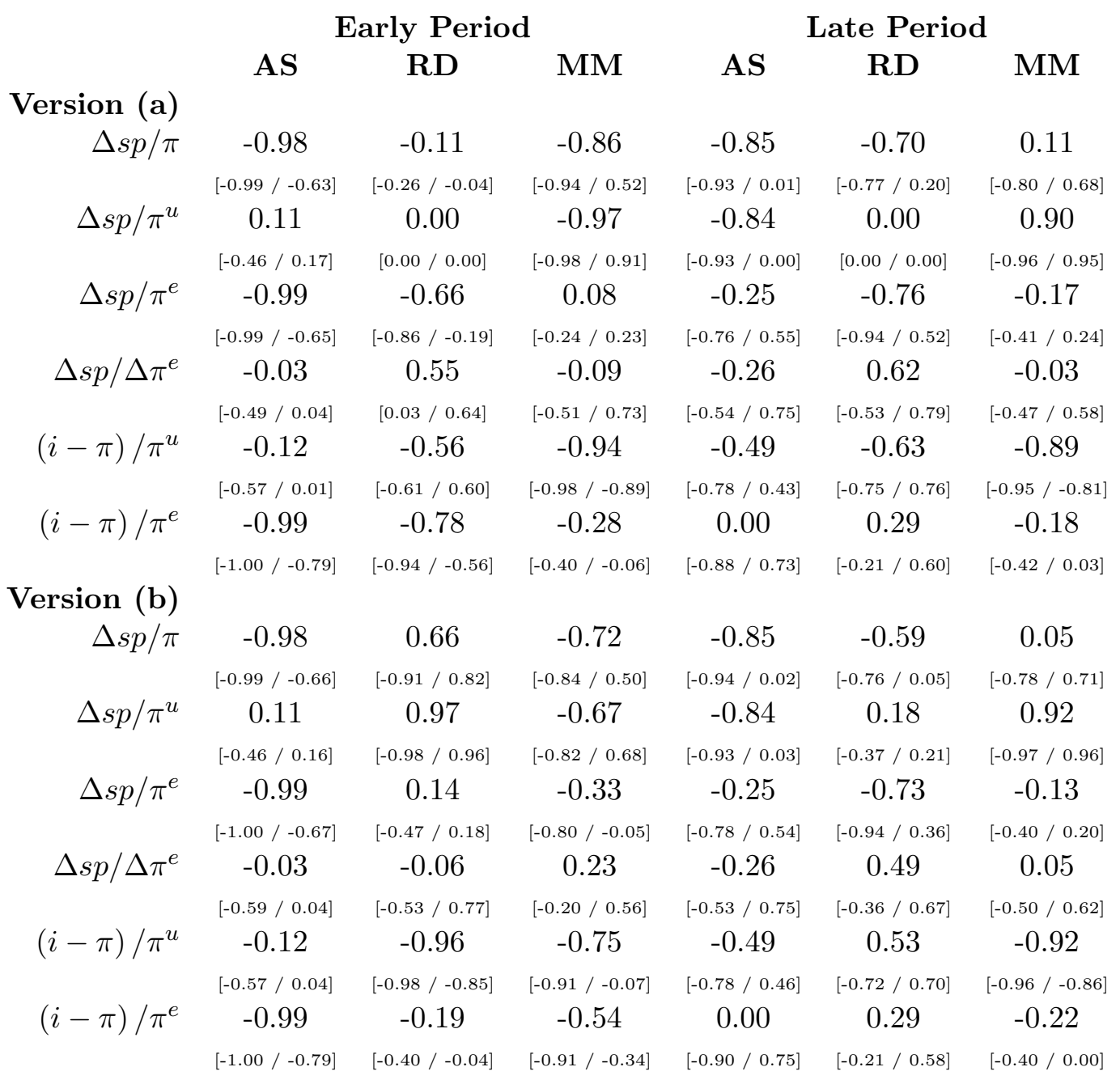




\section{Figure 1}

\section{Impulse Response Functions for Identification Scheme (a)}

This figure shows the reaction of real stock prices, the price level and the real interest rate with respect to aggregate supply (AS), real demand (RD) and money market (MM) shocks. The estimation period is 1953Q1 till 2003Q4 and the impulse response functions are based on identification scheme (a), which is described in the main text. The dotted lines are $90 \%$-confidence intervals around the impulse response functions calculated by the bootstrap.

ev
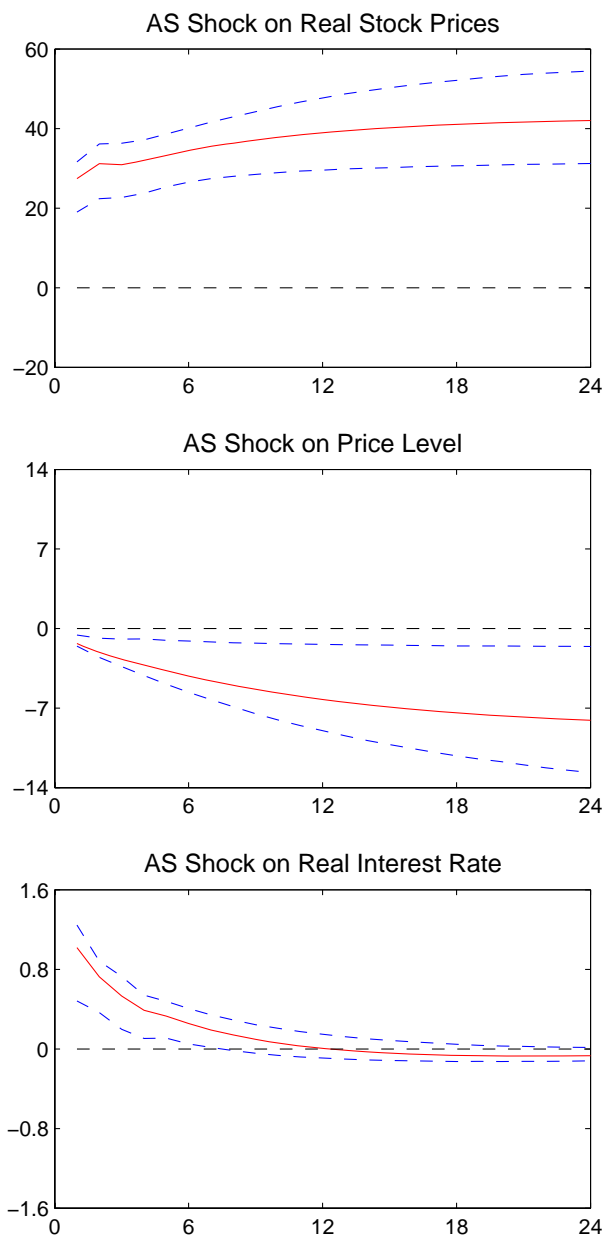

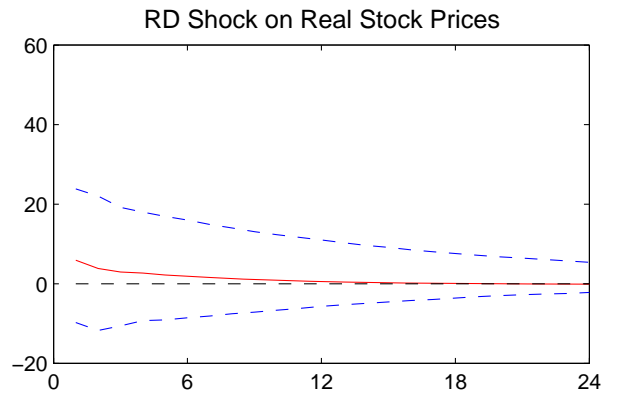

RD Shock on Price Level
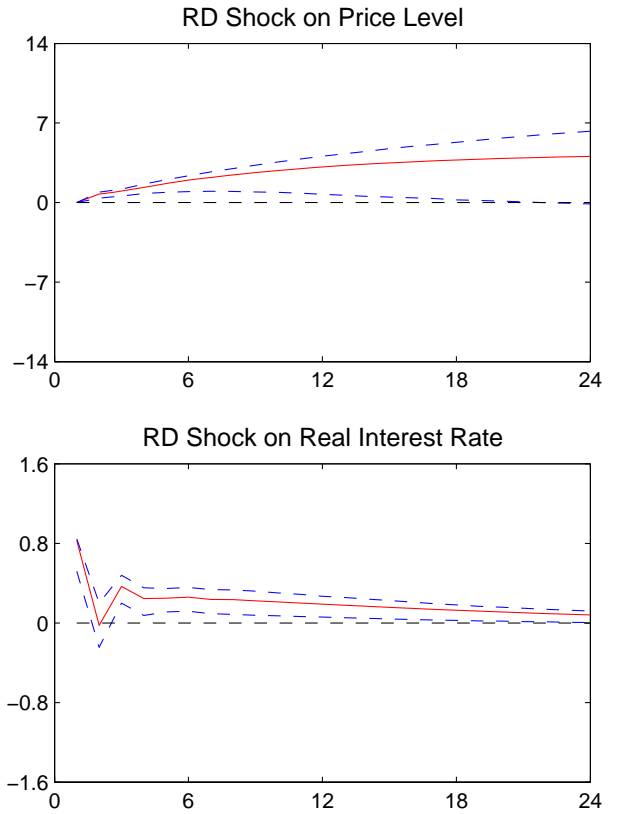
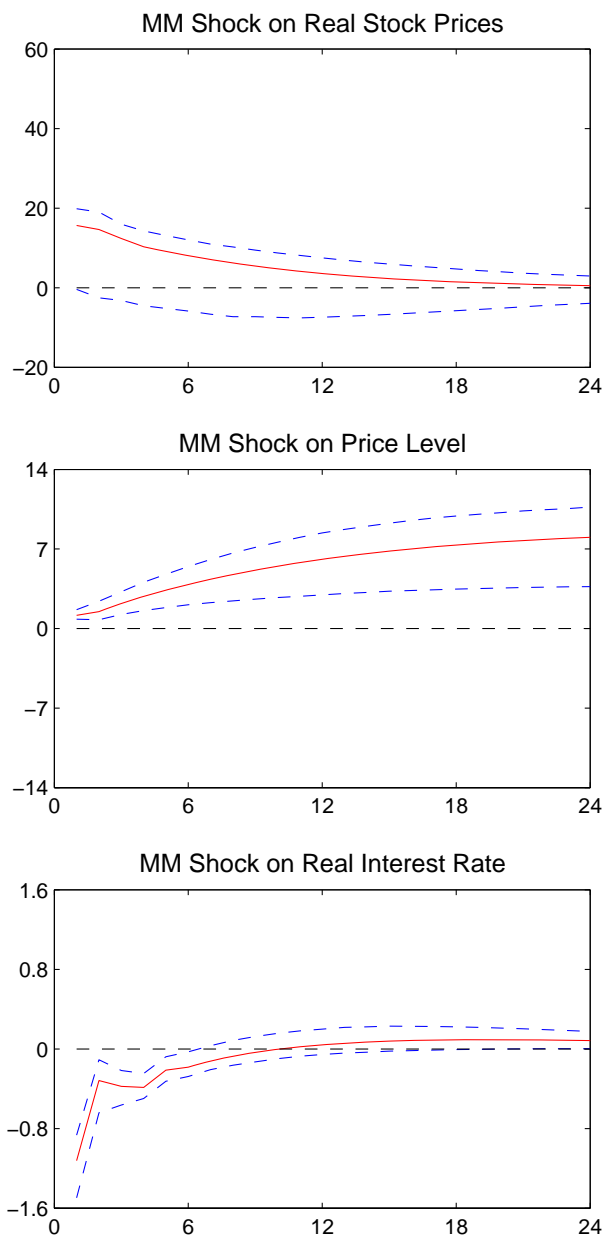


\section{Figure 2}

\section{Impulse Response Functions for Identification Scheme (b)}

This figure shows the reaction of real stock prices, the price level and the real interest rate with respect to aggregate supply (AS), real demand (RD) and money market (MM) shocks. The estimation period is 1953Q1 till 2003Q4 and the impulse response functions are based on identification scheme (b), which is described in the main text. The dotted lines are $90 \%$-confidence intervals around the impulse response functions calculated by the bootstrap.

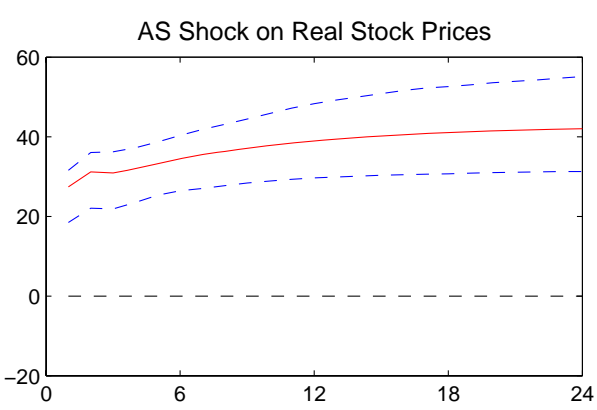

is

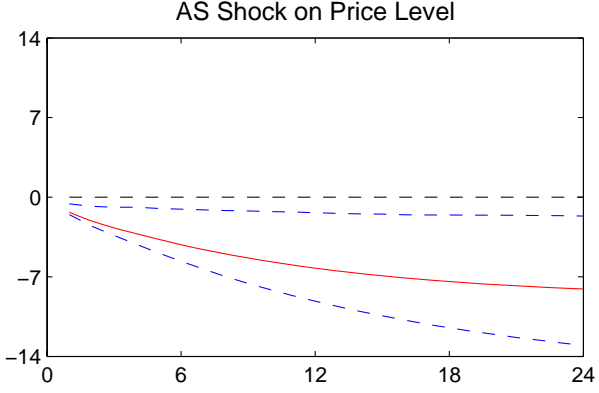

AS Shock on Real Interest Rate

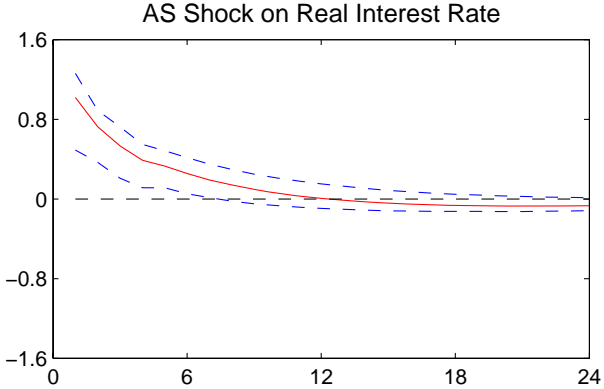

RD Shock on Real Stock Prices

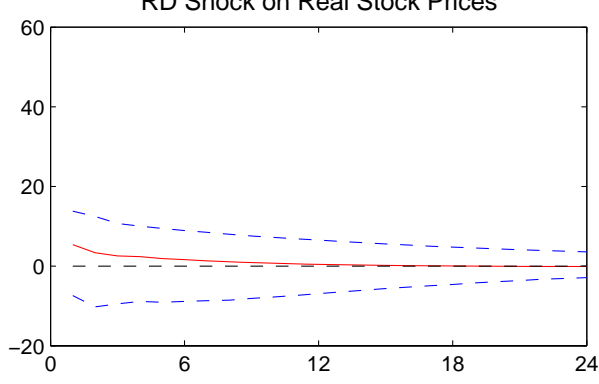

RD Shock on Price Level

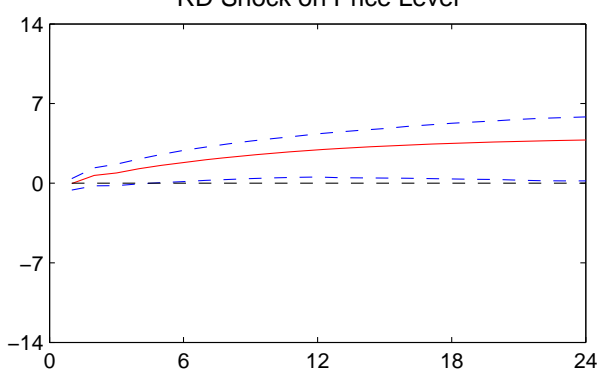

RD Shock on Real Interest Rate

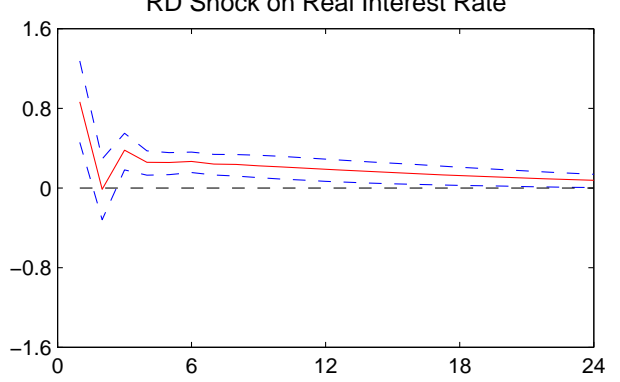

MM Shock on Real Stock Prices

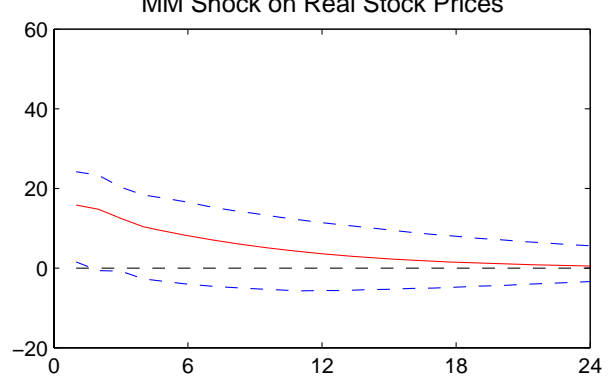

MM Shock on Price Level

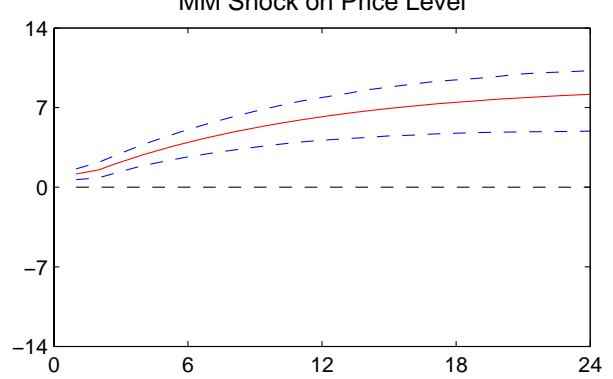

MM Shock on Real Interest Rate

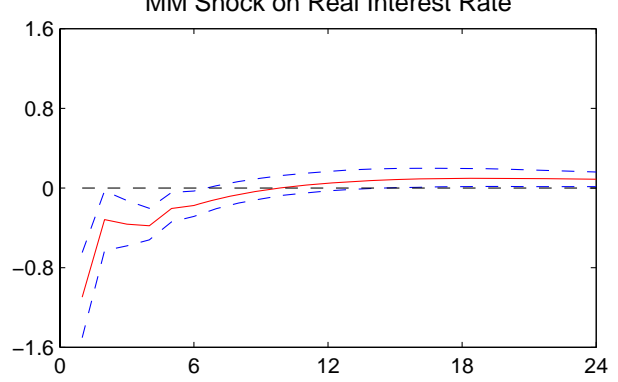




\section{Figure 3}

\section{Structural Decompositions of Real Stock Returns, Inflation and Real Interest Rates}

This figure shows time series plots of the structural decomposition (based on identification scheme (b)) of real stock returns, inflation, and the real interest rate into components driven by aggregate supply (AS), real demand (RD) and money market (MM) shocks. The estimation period is 1953Q1 till 2003Q4.
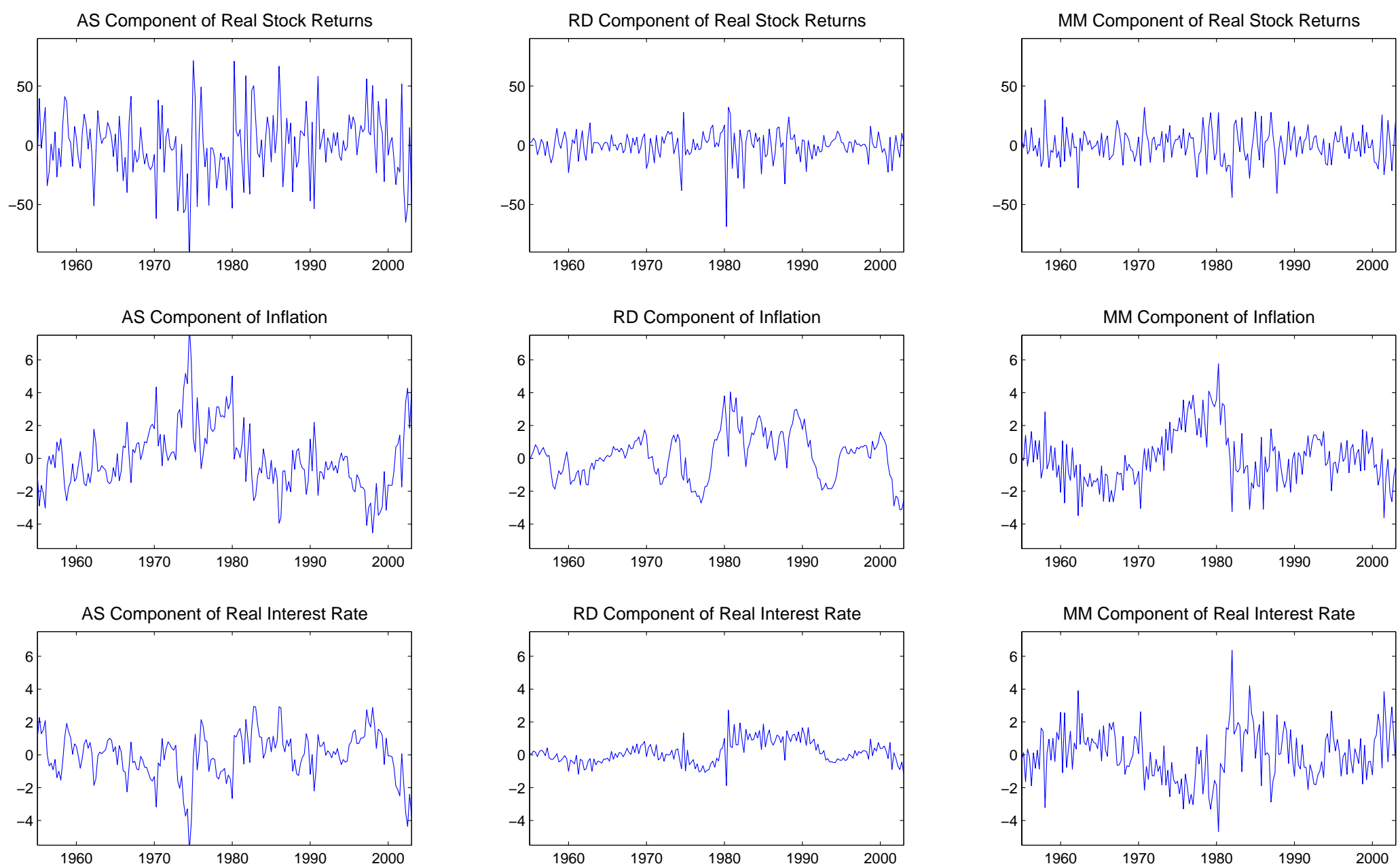


\section{Figure 4}

\section{Real Stock Returns and Real Interest Rate against Inflation and its Structural Components}

This figure shows scatter plots (based on identification scheme (b)) of real stock returns and the real interest rate against inflation and its structural components driven by aggregate supply (AS), real demand (RD) and money market (MM) shocks. The estimation period is 1953Q1 till 2003Q4.
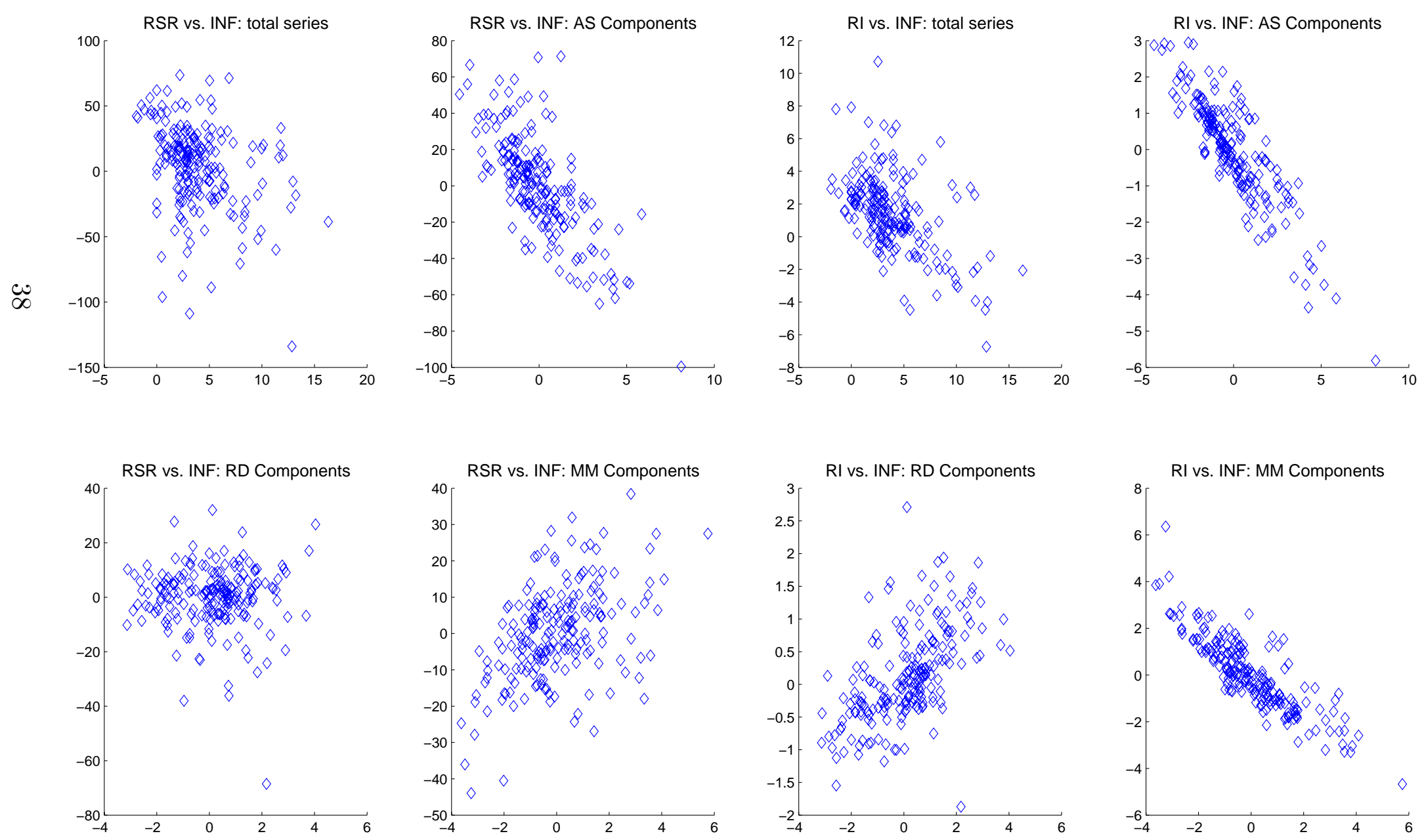


\section{Figure 5}

\section{Impulse Response Functions for the second period (1979Q4 - 2003Q4)}

This figure shows the reaction of real stock prices, the price level and the real interest rate with respect to aggregate supply (AS), real demand (RD) and money market (MM) shocks. The estimation period is 1979Q4 till 2003Q4 and the impulse response functions are based on identification scheme (b), as described in the main text. The dotted lines are 90\%-confidence intervals around the impulse response functions calculated by the bootstrap.

ig
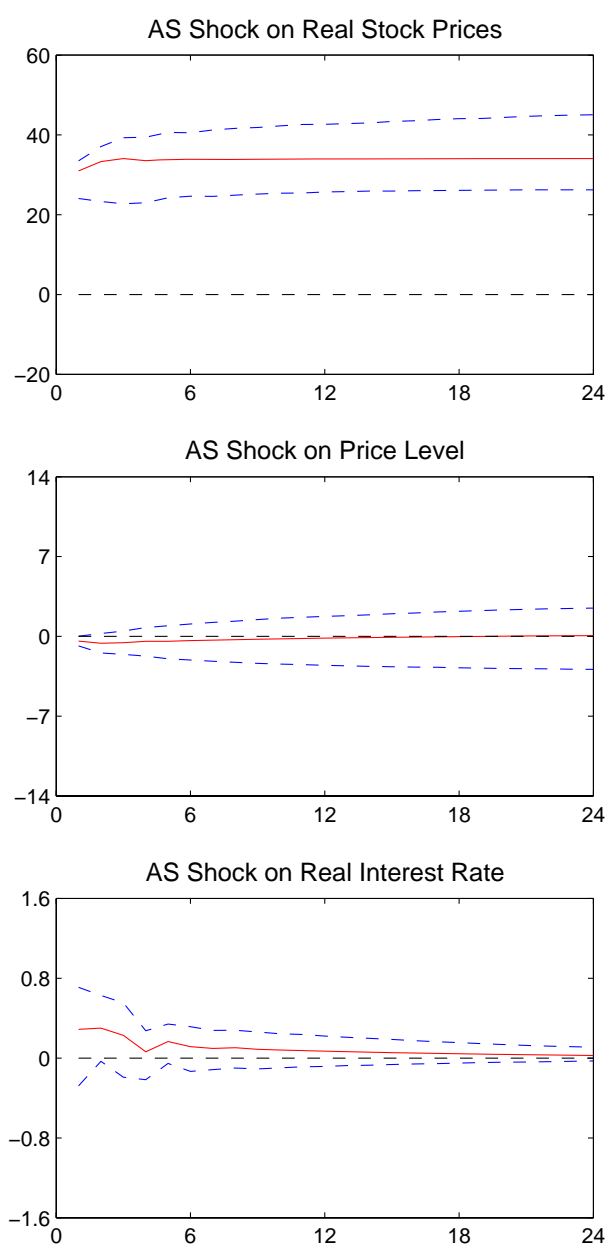
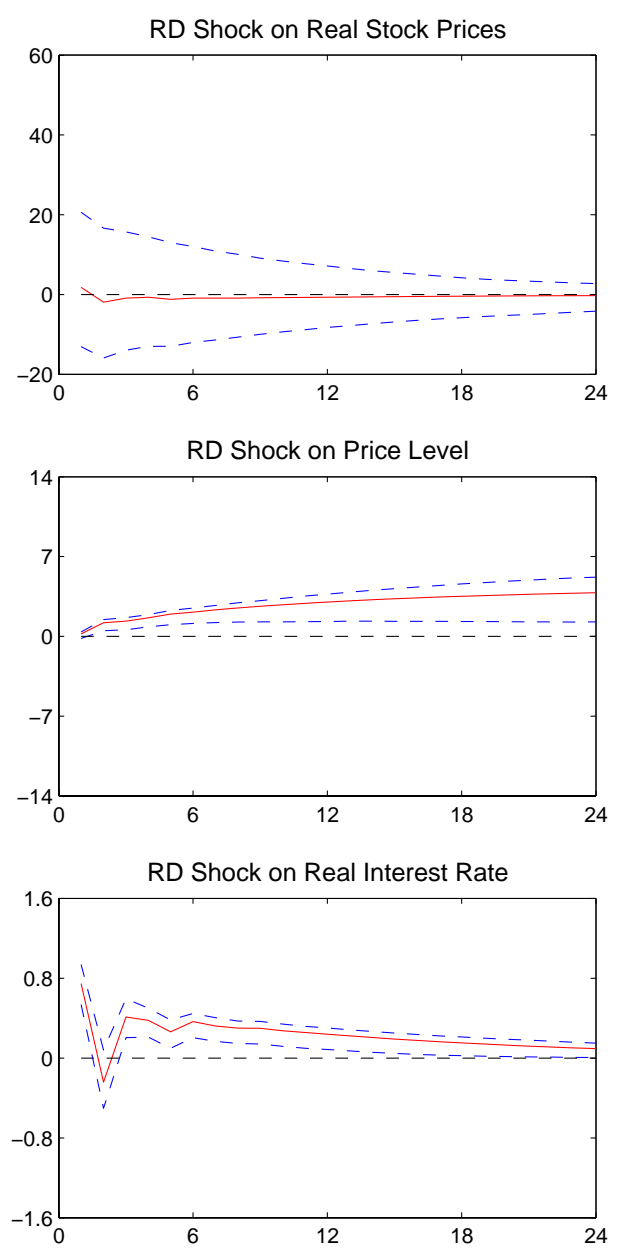
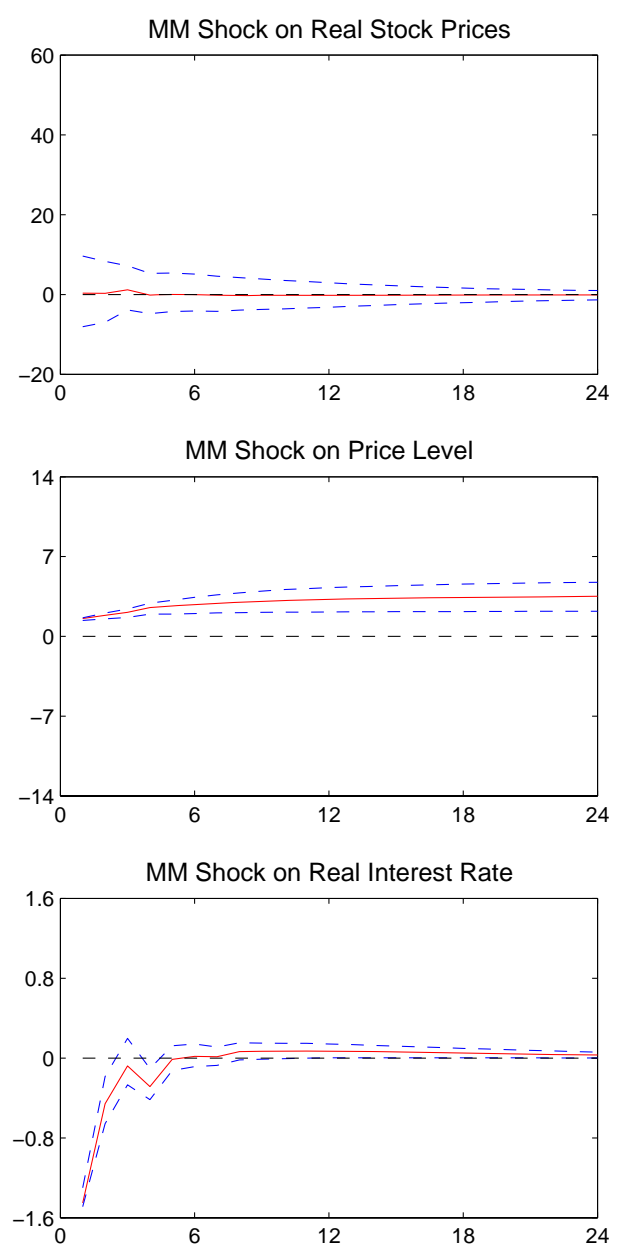